\title{
Inverse modeling of biomass burning emissions using Total Ozone Mapping Spectrometer aerosol index for 1997
}

\author{
Sophia Zhang \\ Department of Earth Atmosphere and Planetary Sciences, Massachusetts Institute of Technology, \\ Cambridge, Massachusetts, USA \\ NASA Goddard Institute for Space Studies, New York, New York, USA
}

Joyce E. Penner

Department of Atmospheric, Oceanic and Space Sciences, University of Michigan, Ann Arbor, Michigan, USA

Omar Torres

Joint Center for Earth Systems Technology, University of Maryland, Baltimore County, Baltimore, Maryland, USA

Received 23 December 2004; revised 12 May 2005; accepted 7 July 2005; published 8 November 2005.

[1] We present results from an inverse model study to determine biomass smoke emissions for the year 1997 by comparison of modeled aerosol index (AI) with that measured by the EP TOMS instrument. The IMPACT model with Data Assimilation Office (DAO) meteorology data in 1997 is utilized to obtain aerosol spatial and temporal distributions. Then a radiative transfer model is applied to generate the modeled AI. A Bayesian inverse technique is applied to optimize the difference between the modeled $\mathrm{AI}$ and the EP TOMS AI in the same period by regulating monthly a priori biomass smoke emissions in seven predefined regions. The modeled AI with a posteriori emissions is generally in better agreement with the EP TOMS AI. The a posteriori emissions from Indonesia increase by a factor of $8-10$ over the a priori emissions due to the Indonesian fires in 1997. The annual total a posteriori source increases by about $13 \%$ for the year 1997 (6.31 Tg/yr black carbon and 67.27 Tg/yr smoke) in the base scenario, with a larger adjustment of monthly emissions. The sensitivity of this result to the a priori uncertainties, the height of the smoke layer, the cloud screening criteria, the inclusion of an adjustment of emissions outside the main biomass burning regions, and the inclusion of the covariances between observations in different locations is discussed in a set of sensitivity scenarios. The sensitivity scenarios suggest that the inverse model results are most sensitive to the assumed uncertainty for a priori emissions and the altitude of aerosol layer in the model and are less sensitive to other factors. In the scenario where the uncertainty of a priori emissions is increased to $100 \%$ (300\% in Indonesia), the total annual black carbon emission is increased to $6.87 \mathrm{Tg} / \mathrm{yr}$, and the smoke emission increases to $73.39 \mathrm{Tg} / \mathrm{yr}$. The a posteriori emissions in Indonesia in the scenario with increased uncertainty are in better agreement with both the TOMS AI and with previous estimates for the Indonesian fires in 1997. In the scenario where biomass smoke from large fires are elevated by $1 \mathrm{~km}$ in altitude, the annual total black carbon emissions are $5.68 \mathrm{Tg} / \mathrm{yr}$, and the smoke emissions are $60.44 \mathrm{Tg} / \mathrm{yr}$, almost unchanged from the a priori emissions.

Citation: Zhang, S., J. E. Penner, and O. Torres (2005), Inverse modeling of biomass burning emissions using Total Ozone Mapping Spectrometer aerosol index for 1997, J. Geophys. Res., 110, D21306, doi:10.1029/2004JD005738.

\section{Introduction}

[2] Biomass burning is a major source of carbonaceous aerosols which contain light absorbing black carbon (BC) as well as organic matter (OM) and other trace constituents. The radiative effect of biomass smoke aerosols is important to both the global and regional radiative budgets [Hobbs et

Copyright 2005 by the American Geophysical Union. 0148-0227/05/2004JD005738 al., 1997; Penner et al., 1998; Podgorny et al., 2003; Davison et al., 2004]. Accurate information on the source strength and geographic distribution of biomass smoke aerosols is essential to quantifying the aerosol forcing and climatic impact of biomass aerosols. There have been continuing efforts to improve biomass burning inventories [Ito and Penner, 2004; van der Werf et al., 2003].

[3] Current biomass emission inventories are developed on the basis of a bottom-up technique, which generates biomass emissions through area burned statistics $\left(\mathrm{m}^{2}\right)$, fuel 
load $\left(\mathrm{g} / \mathrm{m}^{2}\right)$ for that area, combustion fraction, and emission factor $(\mathrm{g} \mathrm{BC} / \mathrm{g}$ or $\mathrm{g} \mathrm{TP} / \mathrm{g})$. Uncertainties in any of these bottom factors will propagate to the final inventory. With about 20 years of data record, the Advanced Very High Resolution Radiometer (AVHRR) instrument provides useful information on the time series of active fires and burned areas [Kaufman et al., 1990]. However, its instrument characteristics are inferior to more recent instruments, such as the SPOT VEGETATION instrument (GBA2000) [Grégoire et al., 2003], the ATSR-2 instrument (GLOBSCAR) [Simon et al., 2004], and the MODIS instrument [Roy et al., 2002; Justice et al., 2002]. Although estimates of burned area have improved with recent satellite remote sensing products, estimates of biomass burned are subject to large uncertainty [Andreae and Merlet, 2001]. For example, the variation of estimated fuel load is about a factor of two globally, using three different tree cover data sets [Ito and Penner, 2004]. Another uncertainty lies in emission factors where the standard deviation of $\mathrm{BC}$ emission factors ranges from $70 \%$ to $100 \%$ among different fuel types [Andreae and Merlet, 2001].

[4] An inverse model was first utilized in atmospheric science by Enting [1993] and Enting et al. [1993] to study the atmospheric $\mathrm{CO}_{2}$ cycle. Later, it was employed to study the atmospheric methane cycle [Hein et al., 1997], and the atmospheric CO cycle [Bergamaschi et al., 2000a]. The inverse model was used to derive the $\mathrm{CO}$ sources by optimizing the difference between a forward model calculation and observations. The method was extended in the work of Bergamaschi et al. [2000b] to produce more robust results by adding constraints to the optimization. Long-term observed surface concentrations were used in these studies. In order to apply this technique to biomass emissions, regionally representative long-term observations of biomass smoke would be needed. However, many surface observations of biomass smoke are campaign based, and hence are inadequate for the development of an inverse model.

[5] Satellite-based measurements provide a convenient and comprehensive method to characterize aerosol temporal and spatial distributions. For example, satellite-retrieved aerosol optical depth (AOD) is frequently used. AOD is the summation of the optical depth due to all aerosol types. Because it is very difficult to separate a specific aerosol from the total optical depth, these measurements are not sufficient to characterize biomass carbonaceous aerosols. However, the global distribution of UV-absorbing aerosols have been measured using the measured differences between two UV band radiances from the TOMS instrument for more than 20 years, starting from November 1978. The use of the TOMS Aerosol Index (AI) to identify absorbing aerosols such as carbonaceous aerosols, mineral dust and ash aerosols from volcanic eruptions was described by Herman et al. [1997], Hsu et al. [1999], and Ginoux et al. [2001]. The TOMS AI detects UV-absorbing aerosols and is less sensitive to pure scattering aerosols, such as sea salt and sulfate aerosols. As a result, the use of the TOMS AI allows a more accurate comparison for absorbing aerosols, such as elevated (at least $2 \mathrm{~km}$ above the surface) biomass carbonaceous aerosols.

[6] In some biomass burning regions, such as the Sahel, biomass smoke is mixed with dust aerosols; therefore dust emissions must be included in the simulation to match the
TOMS AI. Therefore we have combined the results from a chemical transport model and a radiative transport model to simulate the AI for a fixed set of a priori biomass and dust emissions. Once the AI is obtained from the model, an inverse model is used to optimize the difference between satellite measurements and model results by adjusting the biomass source strengths. In this study, we apply the inverse model for the year 1997. The year 1997 is particularly interesting because drought conditions associated with the strong El Niño event triggered widespread increases in fire activity. There have been several studies focusing on the global biomass emissions and biomass emissions in Indonesia for this year using the bottom up approach [Duncan et al., 2003a, 2003b; Levine, 1999; Page et al., 2002; Davison et al., 2004] and inverse modeling technique [van der Werf et al., 2004], which showed considerable variations in their estimates. The inverse model provides a novel way to study biomass emissions in 1997, although the same model can be applied to other years as well.

[7] We will first introduce our chemical transport model, followed by the radiative transfer model and the method to simulate AI combining the transport model and the radiative transfer model. Then the inverse model is employed to obtain better biomass inventories using the modeled AI and the TOMS AI. Finally we will discuss the results of the inverse model in light of several sensitivity studies.

\section{Model Description}

[8] The development of an inverse model for biomass emissions requires calculating the modeled AI which involves several models as illustrated in Figure 1. The components of Figure 1 will be described in the following subsections. The Bayesian inverse technique will be described subsequently.

\subsection{Transport Model}

[9] The IMPACT model is an Eulerian model of transport, transformation and removal, whose spatial resolution in this study is $2^{\circ}$ latitude by $2.5^{\circ}$ longitude. The vertical resolution for this study is 46 sigma levels up to $10 \mathrm{mb}$. In order to simulate the real atmosphere corresponding to the TOMS measurements period, the IMPACT model is driven by the Data Assimilation Office (DAO) Geostationary Operational Environmental Satellite (GEOS) meteorology data for the same time period. Here the meteorology data for the year 1997 are employed.

[10] The IMPACT model is coded to make use of massively parallel computing. The flux form semi-Lagrangian advection scheme is that developed by Lin and Rood [1996]. The parameterization by Balkanski et al. [1993] is employed for wet scavenging in the convective updrafts, while the firstorder rainout parameterization by Giorgi and Chameides [1986] is used for the large-scale precipitation and precipitation in convective anvils. The fraction of aerosol species scavenged in the convective updrafts is:

$$
f=1-e^{-\alpha \Delta z}
$$

where $\alpha$ represents the scavenging efficiency, which is assumed to be $5 \times 10^{-4} \mathrm{~m}^{-1}$ over continents, corresponding to a typical updraft velocity of $10 \mathrm{~m} \mathrm{~s}^{-1}$ [Liu et al., 


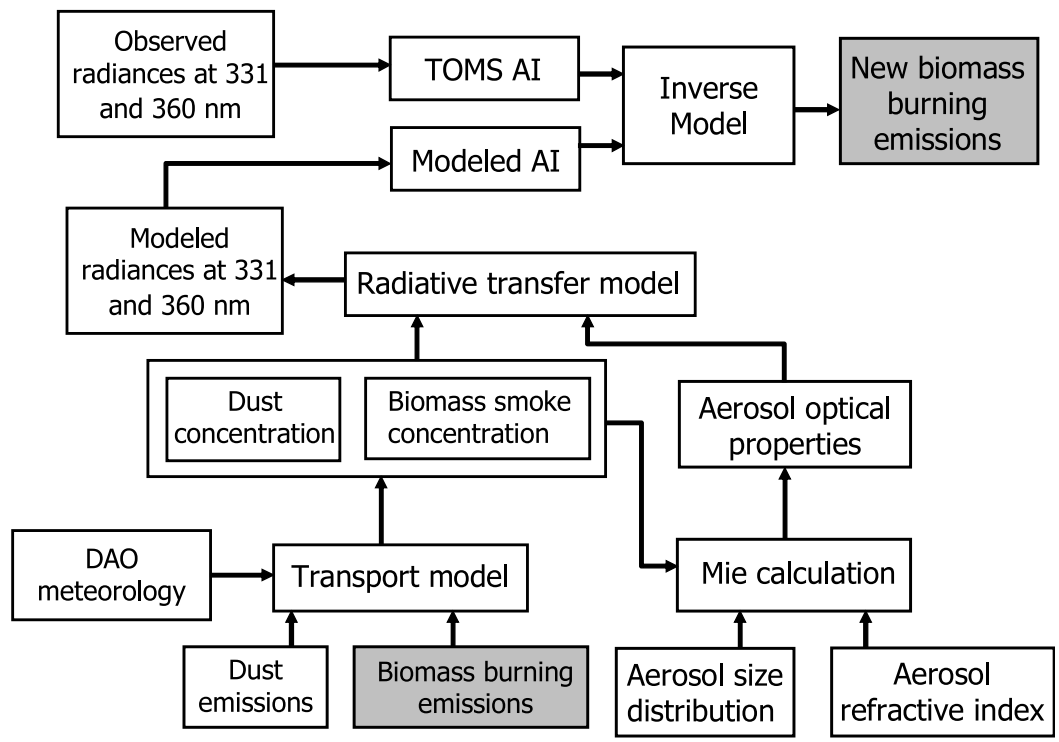

Figure 1. Components of the modeled AI. Besides biomass emissions, dust emissions are included in the calculation of the modeled AI in order to correctly simulate the AI in those regions with both dust and smoke aerosols. However, dust emissions are not optimized by the inverse model and therefore are not plotted here.

2001]. This formulation allows more complete removal for deep convection and partial removal for shallow convection. Washout below the rain is computed by assuming that the loss rate normalized to precipitation is $0.1 \mathrm{~mm}^{-1}$, a typical value derived by Dana and Hales [1976]. Reevaporation is taken into account as well. It is assumed that an arbitrary fraction of $50 \%$ of soluble species is released back to the grid box when evaporation occurs.

[11] The dry deposition scheme for aerosols in the IMPACT model follows the work by Zhang et al. [2001]. This scheme is a resistance in series scheme loosely based on the work of Slinn [1982], taking into account the effect of Brownian diffusion, impaction, interception, and rebound.

[12] The input species for the IMPACT model include biomass black carbon, biomass organic carbon and dust sources. A wide range of factors can influence dust mobilization, including soil moisture, surface conditions and wind velocity. Dust emissions were those generated in the work by Ginoux et al. [2001] as a function of wind speed at 10 meters and the threshold velocity. The emissions in 1997 are used in this work, covering 11 months from January to November. Since dust particles with large radius are not important in long-range transport due to gravitational settling, the current dust emissions are limited to particles with size ranging from 0.1 to $6 \mu \mathrm{m}$. The total dust source strength for the 11 months in the year 1997 is estimated to be $261 \mathrm{Tg}$ for submicron dust particles and $1120 \mathrm{Tg}$ for supermicron dust particles.

\subsection{Methodology for Calculating the AI}

[13] This section first describes how the TOMS AI is calculated on the basis of measured radiances, and then explains the methodology for computing modeled AI.

\subsubsection{TOMS AI}

[14] The Nimbus 7 TOMS operated from November 1978 to May 1993. After that, Meteor 3 TOMS started data acquisition in August 1991 and continued through Decem- ber 1994. For these two instruments, the version 7 TOMS AI was determined for the 340- and 380-nm wavelength channels. No TOMS aerosol data were available from January 1995 to July 1996 until the launch of Earth Probe (EP) TOMS and Advanced Earth Observing Satellite (ADEOS) TOMS. These two instruments do not contain the 340- and 380-nm channel. Instead, the TOMS AI is calculated using the 331- and 360-nm channels. In the recently released version 8 TOMS data, the AI uses 331 and $360 \mathrm{~nm}$ for all sensors. Since this study was carried out before the version 8 TOMS data was released, the version 7 TOMS AI was used instead. However, future analysis will utilize the version 8 TOMS data.

[15] There is an advantage to using the more recent TOMS AI data due to the availability of meteorology data from the DAO and dust emissions. Satellite monitored burned area is available for more recent years, allowing cross comparison between the results of the inverse model and other biomass inventories based on burned area from satellite products, for example, those derived by Ito and Penner [2004]. Because of the loss of ADEOS in June 1997, the TOMS AI used here in this work is the EP TOMS in 1997.

[16] The EP TOMS AI is defined by Herman et al. [1997] as:

$$
A I=-100 \log _{10}\left[\left(I_{331}\right)_{\text {meas }} /\left(I_{331}\right)_{\text {calc }}\right]
$$

where $\left(I_{331}\right)_{\text {calc }}$ and $\left(I_{331}\right)_{\text {meas }}$ are calculated and measured radiances at $331 \mathrm{~nm}$, respectively. $\left(I_{331}\right)_{\text {calc }}$ is determined by requiring that the Lambertian albedo $\mathrm{R}$ in a pure Rayleigh scattering atmosphere at $360 \mathrm{~nm}$ be equal to the measurements, hence $\left(I_{360}\right)_{\text {meas }}=\left(I_{360}\right)_{\text {calc }}$. It should be noted that most surfaces have an albedo that varies with the solar zenith angle so that they are rarely truly Lambertian (the luminance of the surface is the same regardless of the viewing angle). Data containing highly non-Lambertian surfaces, e.g., sea glint and snow/ice, were therefore edited out of our analysis. 
[17] From equation (2), $A I$ can be expressed as:

$$
A I=-100\left\{\log _{10}\left[\left(I_{331} / I_{360}\right)_{\text {meas }}\right]-\log _{10}\left[\left(I_{331} / I_{360}\right)_{\text {calc }}\right]\right\}
$$

where $I_{\text {meas }}$ is the measured backscattered radiance at a given wavelength and $I_{\text {calc }}$ is the radiance calculated at the wavelength in a pure Rayleigh scattering atmosphere. Absorbing aerosols, i.e., elevated (at least $2 \mathrm{~km}$ above the surface) carbonaceous aerosols and mineral dust particles tend to decrease the radiance contrast of the pure Rayleigh background, causing a positive AI. Pure scattering aerosols and clouds, on the other hand, slightly increase the radiance contrast, resulting in nearly zero or a small negative AI. Absorbing aerosols and pure scattering aerosols can be discriminated through the different signs of the AI. When absorbing aerosols and clouds coexist, the AI value can increase or decrease depending on the relative location of the aerosol layer in relation to the cloud, and the level of subpixel cloud contamination. The effect of clouds is discussed in section 5.5.

\subsubsection{Modeled AI}

[18] The modeled AI is calculated on the basis of modeled backscattered radiances, unlike the TOMS AI, which was calculated on the basis of satellite retrieved backscattered radiances. The modeled AI is defined as:

$$
A I=-100\left\{\log _{10}\left[\left(I_{331} / I_{360}\right)_{\text {model }}\right]-\log _{10}\left[\left(I_{331} / I_{360}\right)_{\text {calc }}\right]\right\}
$$

$\left(I_{331} / I_{360}\right)_{\text {model }}$ is the ratio of modeled backscattered radiance at $331 \mathrm{~nm}$ to that at $360 \mathrm{~nm}$ with aerosols in a Rayleigh scattering background. $\left(I_{331} / I_{360}\right)_{\text {calc }}$ is the ratio of modeled backscattered radiances at $331 \mathrm{~nm}$ to that at $360 \mathrm{~nm}$ in a pure Rayleigh scattering atmosphere. The modeled radiance is a function of albedo $\mathrm{R}$ and atmospheric absorption and scattering, where $\mathrm{R}$ is obtained by requiring $\left(I_{360}\right)_{\text {model }}=\left(I_{360}\right)_{\text {calc }}$.

[19] To calculate the modeled AI, we need to know the effect of aerosols on the UV radiance, specifically, the backscattered radiance at the top of atmosphere for the wavelengths 331 and $360 \mathrm{~nm}$. The radiative transfer model used here is a modified version of the code developed by Herman and Browning [1965]. It includes the effects of multiple scattering and polarization. The higher-order scattering is assumed to take place in a plane parallel atmosphere. The radiance of a pure Rayleigh scattering atmosphere is provided by a look-up table. The Rayleigh optical depth at $331 \mathrm{~nm}$ and $360 \mathrm{~nm}$ is same as that used in the TOMS total ozone retrieval [McPeters et al., 1998]. A typical tropical ozone profile with total ozone column of 325 DU [McPeters et al., 1998] is assumed in the model, resulting in an optical depth of about 0.05 at $331 \mathrm{~nm}$. Ozone absorption is very small at $360 \mathrm{~nm}$ $\left(<10^{-8} \mathrm{~atm}-\mathrm{cm}^{-1}\right)$ therefore is neglected in the calculation. The uncertainties in the modeled AI due to the ozone abundance and vertical profile are small, less than $0.5 \%$ [Colarco et al., 2002].

[20] The surface reflectivities at 331 and $360 \mathrm{~nm}$ are based on the monthly Lambert Equivalent Reflectivity (LER) of the Earth's surface at $380 \mathrm{~nm}$ that was developed by Herman and Celarier [1997] using Nimbus 7 TOMS measurements. As indicated in the same work, the difference of the LER at $340 \mathrm{~nm}$ and $380 \mathrm{~nm}$ is less than $0.2 \%$.
The surface reflectivity at $360 \mathrm{~nm}$ is assumed to be equal to that at $380 \mathrm{~nm}$. Additionally, it is assumed that the surface reflectivity at $331 \mathrm{~nm}$ is equal to that at $380 \mathrm{~nm}$. Compared to the reflectivity at visible wavelengths, the land surface reflectivity in the UV range is significantly lower than in the visible and exhibits low spatial variability. Typical values of UV surface reflectivity are about 0.03 for vegetation covered land, and 0.05 to 0.10 for ocean surface. The sensitivity study for biomass smoke aerosols indicates that the absorbing aerosol index is weakly dependent on the surface reflectivity for the regions of interest in this analysis since this analysis is limited to the tropical regions where the UV reflectivity of the surface is always lower than $10 \%$, even for deserts [Torres et al., 1998].

[21] The local passing time is around 11:20 am throughout the operation time of the EP TOMS instrument. Accordingly, the solar zenith angle in the model is calculated for 11:20 am. The computed AI varies by less than $5 \%$ for a difference of 20 degrees in solar zenith angle (not shown here). The satellite viewing angle is assumed to be 0 degrees, the same as that used in the work of Torres et al. [1998]. Since computing the AI on a pixel basis is very time consuming for the inverse modeling application, the TOMS level 3 data are used and the viewing angle is assumed to be nadir in this analysis. The EP TOMS instrument scans perpendicular to the orbital plane from 51 degrees on the left side of the nadir to the 51 degrees on the right. The difference of the modeled AI between a nadir view and that calculated at $40^{\circ}$ is about $18 \%$ for biomass smoke aerosols.

[22] Previous studies indicate that the AI is sensitive to the aerosol vertical distribution, and it cannot easily detect carbonaceous aerosols near the ground [Herman et al., 1997; Torres et al., 1998; Hsu et al., 1999]. The large sensitivity of AI to aerosol height suggests that an inaccurate representation of the aerosol vertical distribution in the transport model may be one of the most important factors contributing to uncertainties in the AI calculation and the inverse model. Not surprisingly, the AI-AOD slope also increases with the aerosol height.

[23] The aerosol size distribution and refractive index used in this study are listed in Table 1 except for biomass smoke aerosol whose refractive index is computed on the basis of the $\mathrm{BC}$ and $\mathrm{OM}$ volume fraction at each grid point, and therefore is different from the value listed in Table 1 . The refractive index for $\mathrm{BC}$ is $1.75-0.46 \mathrm{i}$ [Koepke et al., $1997]$ at $331 \mathrm{~nm}$ and $360 \mathrm{~nm}$, while the refractive index for $\mathrm{OM}$ is assumed to be $1.53-0.0 \mathrm{i}$ at these two wavelengths. The work by Radke et al. [1988] indicated that biomass smoke aerosols showed little variation in smoke aerosol size from fire to fire or during a fire while near the source. The geometric mean radius for biomass is usually around $0.1 \mu \mathrm{m}$ [Radke et al., 1988; Anderson et al., 1996; Remer et al., 1998]. We assume that the geometric mean radius of dry biomass smoke is $0.077 \mu \mathrm{m}$, consistent with the radius of the accumulation mode measured during the TRACE-A experiment [Anderson et al., 1996] and the SCAR-B experiment [Ross et al., 1998; Remer et al., 1998]. Figure 2 shows the relationship between the modeled AI and single scattering albedo and the assumed aerosol geometric mean radius for smoke aerosols with an optical depth equal to 1 at $360 \mathrm{~nm}$. For Figure 2, the aerosol vertical distribution is assumed to be a Gaussian distribution with a mean altitude 
Table 1. Aerosol Size Distributions and Refractive Indices ${ }^{\mathrm{a}}$

\begin{tabular}{lcccccccc}
\hline & & & & & & & \multicolumn{2}{c}{ Refractive Index } \\
\cline { 7 - 9 } Aerosol Type & $\mathrm{r}_{1}, \mu \mathrm{m}$ & $\sigma_{1}$ & $\mathrm{~N}_{1}$ & $\mathrm{r}_{2}, \mu \mathrm{m}$ & $\sigma_{2}$ & $\mathrm{~N}_{2}$ & $331 \mathrm{~nm}$ & $360 \mathrm{~nm}$ \\
\hline Biomass smoke & 0.077 & 1.40 & 1.0 & $\ldots$ & $\ldots$ & $\ldots$ & $1.54-0.018 \mathrm{i}$ & $1.54-0.018 \mathrm{i}$ \\
Dust & 0.045 & 1.6 & 1.6 & 0.28 & 2.5 & 0.96 & $1.57-0.0048 \mathrm{i}$ & $1.57-0.0040 \mathrm{ii}$ \\
\hline
\end{tabular}

${ }^{a}$ Refractive index for biomass smoke is the value inferred during the SAFARI 2000 campaign at $550 \mathrm{~nm}$ [Haywood et al., 2003], assuming there is no wavelength dependence. Dust refractive index is from Colarco et al. [2002].

of $3 \mathrm{~km}$ and $\sigma$ equal to $1.5 \mathrm{~km}$. The refractive indices are those listed in Table 1. The refractive index for biomass smoke is that observed during the SAFARI 2000 campaign [Haywood et al., 2003]. The modeled AI is anticorrelated with the single scattering albedo. The modeled AI reaches its minimum while the single scattering albedo reaches its maximum when the geometric mean radius is approximately $0.1 \mu \mathrm{m}$. Since the modeled AI is not very sensitive to variations in the geometric mean radius between 0.02 and $0.1 \mu \mathrm{m}$, the uncertainty associated with the assumed size distribution of biomass smoke aerosol is relatively small for the size range of interest.

[24] The dust size distribution is that measured during the ACE 2 experiment near Tenerife, Canary Island [de Reus et al., 2000]. However, only the accumulation mode and coarse mode are used here because the cross section of the Aitken mode particles is small and hence unimportant in the radiative transfer calculation. Omitting the Aitken mode only results in a small difference (1\%) in the modeled AI. The dust refractive index was obtained by fitting the slope of the AI and AOD relationship with observations at the AERONET sites [Colarco et al., 2002]. Colarco et al. [2002] inferred the dust refractive index using three different size distributions including the one we used here [de Reus et al., 2000]. We assume an imaginary component of the refractive index that was $20 \%$ larger than the value at $360 \mathrm{~nm}$ used by Colarco et al. [2002]. Colarco et al. [2002] found that the inferred imaginary component of the dust refractive index is much smaller than the previous value used in the TOMS retrieval [Torres et al., 2002]. The retrieved dust refractive index at AERONET sites [Dubovik et al., 2002] and that by Sinyuk et al. [2003] also suggests that dust aerosols are less absorbing than previously thought [Patterson et al., 1977]. The refractive indices given by Dubovik et al. [2002] and by Sinyuk et al. [2003] are very similar to what we used here. The uncertainty of the real component of the refractive index contributes less than $5 \%$ difference in the modeled AI. The uncertainty in the inverse model introduced by the dust refractive index can be minimized by carefully removing data points with large dust contamination. The dusty regions are identified by calculating the ratio between the optical depth of dust and biomass smoke. When the ratio is greater than 1 , that region is assumed to have large dust contamination, and is not included in this analysis.

[25] The AI is calculated from the modeled concentrations of smoke and dust at each grid box with the aerosol vertical distribution taken from the transport model. Since the radiative transfer calculation is very time consuming, the software Parallel Virtual Machine (PVM) is employed to distribute the calculation on multiple workstations. Although the overall performance depends on the number of workstations and the load on each node, the wall clock time needed to run the simulation is reduced tremendously because of low internode communication.

[26] The modeled AI used in the inverse model is computed on the basis of monthly average aerosol concentrations in order to reduce computation time. This may introduce a bias, since observations took place daily. To evaluate this bias, two simulations are carried out for January 1997, one with the AI calculated on the basis of the daily aerosol concentrations at noon, and the other based on monthly mean aerosol concentrations. The monthly average of the daily AI is calculated from the first simulation and compared to the result with monthly average aerosol concentrations. The relative difference from this calculation is about $\pm 5 \%$ on average with most regions having a relative difference of less than $\pm 10 \%$. The overall tendency is to underestimate the monthly average AI if the monthly average aerosol concentration is used for the calculation, probably because of an underestimation of the aerosol height in the monthly mean aerosol concentrations. There are some points with a relative difference as large as 30\% in North Africa. These large differences are due to the very small AI value $(<0.2)$ there. In this study, we avoid using data points with AI less than 0.4 which helps to reduce the bias introduced by the use of monthly average aerosol concentrations. Therefore the relative error due to using monthly average aerosol concentrations is about $5 \%$.

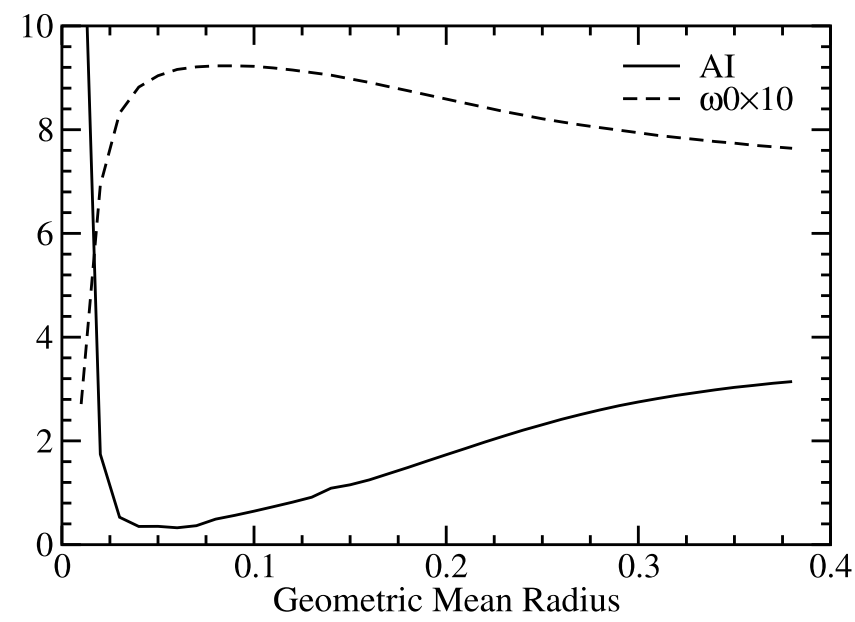

Figure 2. Relationship between the model AI and the single scattering albedo at $360 \mathrm{~nm}$ and the assumed geometric mean radius for biomass smoke aerosols. The aerosol size distribution is assumed to be a lognormal distribution with $\sigma$ equal to 1.40 . The $\mathrm{BC}$ fraction is assumed to be $10 \%$. The aerosol optical depth at $360 \mathrm{~nm}$ is 1. The mean altitude of the aerosol layer is $3.0 \mathrm{~km}$. The surface reflectivity is 0.05 . 
[27] Hsu et al. [1999] derived the slope of AOD (AOD was referred to as aerosol optical thickness (AOT) in their study) at $380 \mathrm{~nm}$ measured by Sun photometer and the EP TOMS AI at the AERONET sites for South American and African smoke in the years 1997 and 1998. The interannual difference of the slope from the AOD and AI relationship in their results was small, providing a way to check the modeled AI for the year 1997 in this work. We calculate AI using the aerosol vertical distribution in the transport model. The refractive index for biomass smoke aerosols at each site is computed on the basis of the volume fraction of $\mathrm{BC}$ and $\mathrm{OM}$. The size distributions for biomass smoke and dust are those listed in Table 1. The satellite viewing angle is assumed to be the nadir view. The slope of the 380-nm AOD and the modeled AI is 1.20 in South America, very close to the slope of 1.25 in the work by Hsu et al. [1999]. In Africa, the calculated AOD and AI slope is 0.62, which is somewhat smaller than the slope of $0.77-0.84$ obtained by Hsu et al. [1999]. The difference between the model and observations in Africa is due to the contamination of dust particles in the model, since the observed AOD and AI slope for dust was about 0.3-0.4 [Hsu et al., 1999]. Dust has little impact on the results for South America because of low dust concentrations there. The difference between the South America and Africa in the observation and in the model can be attributed to the difference in the $\mathrm{BC}$ mass fraction and the aerosol vertical distribution. Smoke from African fires, which largely comes from savannah burning, has a larger $\mathrm{BC}$ mass fraction in our inventories, resulting in a slightly larger imaginary component of the refractive index for smoke aerosols in Africa. The transport model also produces a more elevated aerosol layer in Africa, consistent with the LIDAR measurements during the TRACE-A experiment [Browell et al., 1996]. Both of these two factors tend to cause a smaller AOD and AI slope than that in South America.

\subsection{Inversion Technique}

[28] Here, we adopt the Bayesian inversion approach described by Tarantola and Vallette [1982a, 1982b]. This approach was used by Hein et al. [1997] for $\mathrm{CH}_{4}$ inversion. Whereas Hein et al. [1997] optimized $\mathrm{CH}_{4}$ sinks by treating them as negative sources, this approach suffers the disadvantage that the mixing ratio of $\mathrm{CH}_{4}$ needs to be prescribed by the forward model since the removal process is proportional to the atmospheric mixing ratios. The range of global aerosol burdens from different models is about a factor of 2.5 for carbonaceous aerosols as demonstrated by Penner et al. [2001]. The range of surface mixing ratios is about a factor of 10. Prescribing aerosol mixing ratios can introduce a large systematic error in the inverse model. Therefore optimizing individual sinks is not included in this work.

[29] The inverse technique constitutes a least squares optimization problem. The general form of the Bayesian least squares is

$$
S=(\mathbf{c}-\mathbf{h}(\mathbf{x}))^{\mathbf{T}} \mathbf{O}^{-1}(\mathbf{c}-\mathbf{h}(\mathbf{x}))+\left(\mathbf{x}-\mathbf{x}_{\mathbf{a}}\right)^{\mathbf{T}} \mathbf{B}_{\mathbf{a}}^{-1}\left(\mathbf{x}-\mathbf{x}_{\mathbf{a}}\right)
$$

where $S$ is the least squares cost function which we try to minimize, and $\mathbf{c}$ and $\mathbf{h}(\mathbf{x})$ are vectors representing the observations and model results at a series of grid points, respectively. The superscript ${ }^{\mathbf{T}}$ represents the transpose operator of a vector or matrix. $\mathbf{x}$ are the derived emissions, and $\mathbf{x}_{\mathbf{a}}$ are the a priori emissions. $\mathbf{O}$ and $\mathbf{B}_{\mathbf{a}}$ are the covariance matrix for the observations and a priori emissions, respectively. The covariance matrix is composed in such a way that the diagonal elements are the variances of the observations at a single point or the a priori emissions for a single region, and the off-diagonal elements give the covariances between two locations or two emissions, calculated as:

$$
\operatorname{cov}\left(x_{i}, x_{j}\right)=\frac{1}{n-1} \sum_{k=1}^{n}\left(x_{i, k}-\bar{x}_{i}\right)\left(x_{j, k}-\bar{x}_{j}\right)
$$

where $x_{i}$ and $x_{j}$ represent the observations or a priori emissions at two locations, $i$ and $j$, respectively, $\bar{x}_{i}$ and $\bar{x}_{j}$ are the means of $x_{i}$ and $x_{j}$, respectively, and $\mathrm{k}$ is the index over which the mean is calculated.

[30] Since most transport processes in the model and the AOD are approximately linear in the aerosol mixing ratios, a linear relationship between the modeled AI and AOD ensures that the modeled AI can be expressed as a linear combination of the model solution for each individual biomass smoke emission, in our case, biomass smoke emission in a specified region. Therefore

$$
\mathbf{h}(\mathbf{x})=\mathbf{T x}
$$

where $\mathbf{T}$ is the model response matrix to biomass burning emissions in a specific region, $\mathbf{h}(\mathbf{x})$ is the modeled AI for a set of emissions $\mathbf{x}$. Given the source strength $\mathbf{x}$, equation (7) can be used to estimate the AI directly.

[31] The formal solution to equations (5) and (7) is

$$
\mathbf{x}=\mathbf{x}_{\mathbf{a}}+\mathbf{B T}^{\mathbf{T}} \mathbf{O}^{-\mathbf{1}}\left(\mathbf{c}-\mathbf{h}\left(\mathbf{x}_{\mathbf{a}}\right)\right)
$$

$$
\mathbf{B}=\left[\mathbf{T}^{\mathrm{T}} \mathbf{O}^{-1} \mathbf{T}+\mathbf{B}_{\mathbf{a}}^{-1}\right]^{-1}
$$

[32] If the further assumption is made that the uncertainty of the observations and emissions are independent of each other, $\mathbf{O}$ and $\mathbf{B}_{\mathbf{a}}$ are each diagonal, with diagonal elements equal to the variances $\left(\sigma^{2}\right)$ of observations and the a priori emissions, respectively.

[33] There are two terms in equation (5). The first term is the weighted least squares difference of the observation and the model data; the second term is the weighted least squares difference of the a priori and the a posteriori emissions. The use of the linear estimation, equation (7), and equation (5) allows the systematic propagation of the uncertainty in the data to the uncertainty of the a posteriori emissions (equation (8)). If the observation indeed provides constraints to the a posteriori emissions, the uncertainties of the a priori emissions will be reduced. Otherwise, the uncertainties of the a posteriori emissions will remain unchanged from the a priori uncertainties. The use of prior estimates in equation (5) is necessary, since without such information, the solutions may be unstable [Denning, 1994]. If the observational error is much smaller than that of the a priori emissions, the solution will force the model to match the observations. On the other hand, if the observational error is large compared to the a priori emissions, then the a 


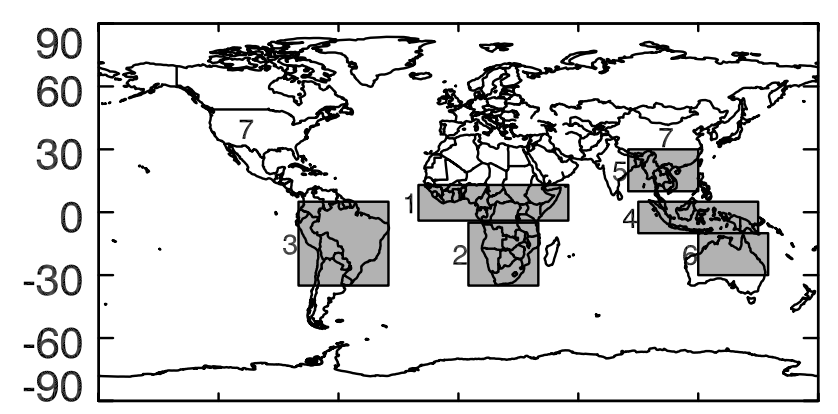

$\begin{array}{lllllll}-180 & -120 & -60 & 0 & 60 & 120 & 180\end{array}$

Figure 3. Biomass burning regions considered in the inverse model. The regions refer to Sahel (region 1), southern Africa (region 2), South America (region 3), Southeast Asia (region 4), Indonesia (region 5), Australia (region 6), and the rest of the world (unshaded regions, region 7).

posteriori emissions are close to the a priori emissions. The uncertainties of the observations and the a priori emissions are discussed in sections 4 and 3, respectively.

[34] Since aerosols have a lifetime of about a week in the model, the impact of perturbing emissions in prior months is neglected in this work. The inverse model is carried out for each month separately. This approach can be improved by adding the model response matrix $\mathbf{T}^{\prime}$ to the biomass burning emissions in the previous month to equation (7). Thus equation (7) becomes:

$$
\mathbf{h}\left(\mathbf{x}, \mathbf{x}^{\prime}\right)=\mathbf{T} \mathbf{x}+\mathbf{T}^{\prime} \mathbf{x}^{\prime}
$$

where $\mathbf{x}^{\prime}$ is the vector representing the biomass burning emissions for the previous month. In the future, we plan to examine the effects of including emissions from the previous month.

\section{Biomass Smoke Emissions}

[35] The a priori biomass smoke emissions used here were constructed by Liousse et al. [1996]. The annual emission strengths were 59.9 $\mathrm{Tg}$ smoke and 5.63 Tg BC, including savannah, forest, agriculture, and domestic fires. In their biomass burning inventory, fires from temperate and boreal regions were not included. The forest and savannah fires followed the work of Hao et al. [1990] with updated emission factors, resulting in annual emissions of 2.17 and $1.93 \mathrm{Tg} \mathrm{BC} / \mathrm{yr}$ for savannahs and tropical forests. Domestic fires and agriculture fires were constructed in the study by Liousse et al. [1996] through an exhaustive literature survey. The annual emissions for domestic fires and agriculture fires were 0.53 and 1 . Tg BC/yr, respectively.

[36] Dividing the current biomass emissions into subcategories according to the type of biomass burned is straightforward. However, optimizing the biomass smoke emissions on the basis of the type of biomass will not be able to reduce the uncertainty of emissions that are allocated by geographic regions. For example, the relative emission strength of forest burning in Indonesia and South America might not be accurate in the a priori inventory. Optimizing the biomass emissions from forested areas, which are present in both
South America and Indonesia, would fail to catch the regional ratio of emissions. Dividing biomass burning emissions according to their geographic locations has been used in previous studies [Duncan et al., 2003b; Galanter et al., 2000; Arellano et al., 2004]. In this study, the a priori biomass emissions are partitioned according to geographical regions as well. First, the map is divided into seven geographical regions. Then emissions are portioned according to their locations. These separate regions are then used in the calculation of burden and the TOMS AI from the different regions. The source in each region is optimized individually.

[37] It is assumed that the biomass burning in different regions is not correlated with the emissions in other regions and that their uncertainties are independent of the observations. In order to achieve independence between the individual source regions, fairly large regions are used, avoiding partitioning of areas with similar burning patterns. Unfortunately, since forest and savannah burning in the tropics is closely associated with the dry season, burning in different regions are potentially correlated. Additionally, the uncertainty of biomass emissions in a region is associated with the uncertainty of emission factors which are applied uniformly for the same vegetation type despite different regions. This undermines the assumption of the independent uncertainty of biomass emissions in each region. Daily emissions are needed in order to calculate the covariance in a particular month between the emissions in two subregions. Since there is not enough information provided to calculate this covariance, the covariance of the a priori emissions in different regions is simply set to zero, leaving the covariance matrix $\mathbf{B}_{\mathbf{a}}$ in equation (5) diagonal.

[38] The independence of observations and a priori emissions is also difficult to establish, since current biomass emissions may implicitly or explicitly utilize information based on observations. However, the a priori emissions used here do not take into account any information collected through the TOMS AI products. Therefore the independence between a priori emissions and observations is a valid assumption. If this assumption were not true, the uncertainties of the a priori emissions would be underestimated.

[39] The potential weakness of dividing the sources into large regions is that geographic variations within each region are not subject to optimization. However, this is a trade off needed to gain independence between a priori sources. Figure 3 plots the 6 major source regions for biomass burning that are used here. They are (1) the Sahel (including equatorial Africa), (2) southern Africa, (3) South America, (4) Southeast Asia, (5) Indonesia, and (6) Australia. Then whatever is left in the emissions which are not included in the first defined six regions is categorized as the rest of the world (region 7). The temperate and boreal regions are not included, but India is included in the a priori emissions. This means the emissions in the temperate and boreal regions where TOMS is uncertain are not adjusted in this study. India is an important biomass emission region where burning (except domestic fires) occurs from January to May. However, there is a substantial amount of dust aerosols during this period, making optimization of biomass smoke emissions more difficult. In a preliminary simulation, optimization including biomass emissions in India resulted in negative a posteriori emis- 
sions in India in the major biomass burning months (March, April, and May). Dust contributes a large fraction (about $50 \%$ or more) to the combined optical depth for dust and biomass smoke. The inverse model fails because it only adjusts the biomass emissions in India whereas the discrepancy between the observed and modeled AI comes from both dust and biomass smoke. Optimizing dust emissions is beyond the scope of the present study, so that biomass emissions in most parts of India are excluded from the optimization. The small region near the Bay of Bengal is included as part of the Southeast Asia region. The first six major source regions contribute about $67 \%$ of the total biomass smoke a priori emissions.

[40] The uncertainties associated with the a priori biomass burning emissions were not estimated by Liousse et al. [1996]. Biomass black carbon emissions range from 5.6 to 9 in different studies [Liousse et al., 1996; Cooke and Wilson, 1996; Scholes and Andreae, 2000]. The reported biomass burned in the tropics ranges from 3260 to $10450 \mathrm{Tg} / \mathrm{yr}$ [Seiler and Crutzen, 1980; Crutzen and Andreae, 1990; Andreae, 1991; Hao and Liu, 1994; Galanter et al., 2000]. The actual range of uncertainty may encompass both larger and smaller values. Here, we assume that the uncertainty of biomass burning emissions is a factor of 2 and that this uncertainty represents a $95 \%(2 \sigma)$ confidence interval. For the base scenario, we assume that the standard deviation of each individual biomass source in regions 1,2, 3, 4, and 6 is $50 \%$ of the a priori source, while in Indonesia (region 5) the standard deviation is assumed to be $200 \%$ of its source, because of the large fires in that region in 1997 [Page et al., 2002]. The biomass emissions in the rest of the world (region 7) are fixed in the base case, and hence have a standard deviation of 0 . The assumption that the biomass emissions in the five regions have a uniform relative standard deviation is a simplification since in reality the uncertainties of biomass emissions vary in different regions. For example, the areas associated with savannah and forest burning in Africa are uncertain to a factor of 2 [Lacaux et al., 1995]. The biomass burning in South America is uncertain by a factor of 2.5 [Ito and Penner, 2004]. Underestimating the uncertainty of a priori biomass emissions tends to undermine the model capability to further reduce the uncertainties through optimization. This issue will be discussed in section 5.2.

\section{Observed TOMS AI}

[41] The TOMS satellite observations are used in the inverse model. The advantage of using remote sensing data compared to in situ point observations is that remote sensing data represent grid average values better than do point observations, thereby causing less error due to the spatial mismatch between the model and observations. On the other hand, satellite remote sensing data have the disadvantage of instrument error, information loss due to the inversion algorithm used to infer the observation from radiances, and cloud contamination. Another uncertainty of satellite remote sensing data comes from the "space-filling" algorithm used to fill a grid area without $100 \%$ coverage by the satellite.

[42] The monthly average AI is calculated on the basis of the daily Level 3 EP TOMS AI with a resolution of $1 \times$
1.25 degrees. The use of the TOMS Level 3 data provides better agreement with the spatial resolution of the transport model $(2 \times 2.5$ degrees $)$, although the information from the viewing angle is lost. In order to compare to the observations, the $1 \times 1.25$ degree TOMS AI data are interpolated to the $2 \times 2.5$ degree resolution of the model. These data are then used to compute the monthly mean, daily standard deviation and covariance between two locations. A cloud screening criteria (discussed below) is used in the calculation in order to reduce cloud contamination. The standard deviation and covariance of the observational data are calculated from the available daily TOMS data and their corresponding monthly mean value.

[43] In the base case, the covariance between two locations is neglected. Therefore the covariance matrix is diagonal with only the variance of each location as the diagonal elements. When off-diagonal elements are included in the matrix, the situation is more complicated. The results without omitting off-diagonal covariances are discussed in section 5.6.

[44] Another important factor which affects our inversions is the cloud screening method. The monthly mean TOMS AI in each month from January to December without cloud screening is plotted in Figure 4. Using a reflectivity of $40 \%$ to eliminate cloud contamination leads to similar results (not shown here). However, the monthly mean TOMS AI is notably smaller if a stricter cloud screening (lower reflectivity) criteria is used (not shown). There are two possible reasons for this. First, high-aerosol events increase the reflectivity, which would therefore be eliminated by using the low-reflectivity criteria. Second, clouds can increase the AI if absorbing aerosols are located above them (see Figure 11). For the base scenario, we apply a cloud screening criteria using a reflectivity of $40 \%$. The effects of clouds will be discussed in detail in section 5.5.

[45] The seasonality of biomass burning is visible in the monthly TOMS AI plot (Figure 4). Biomass burning in the Sahel occurs during the winter months. The biomass burning season in South East Asia peaks in March and April with weaker burning in February. Biomass burning in southern Africa starts in June and intensifies in the following months, reaching its peak in July and August. Biomass burning in South America starts later than in southern Africa. There are smoke signals in August, September, October and November. The widespread fires in Indonesia during 1997 due to the dry conditions driven by an El Niño event has a strong signal from August through November in the EP TOMS AI plot. There is no representation of this fire in the current biomass burning emissions. However, we do have prior ground-based knowledge of the Indonesia fires. Hence the standard deviation is assumed to be $200 \%$ of the source. The emissions in Indonesia provide a test to evaluate how the inverse model performs with poor a priori information.

[46] Since the TOMS AI cannot discriminate between dust and biomass smoke aerosols, special attention must be paid to those regions where aerosols are a mixture of dust and biomass smoke. Including those data points with large dust concentrations tends to degrade the a posteriori emissions since the inverse model is only allowed to adjust the a priori biomass emissions although part of the discrepancy between the TOMS AI and the modeled AI may come from 

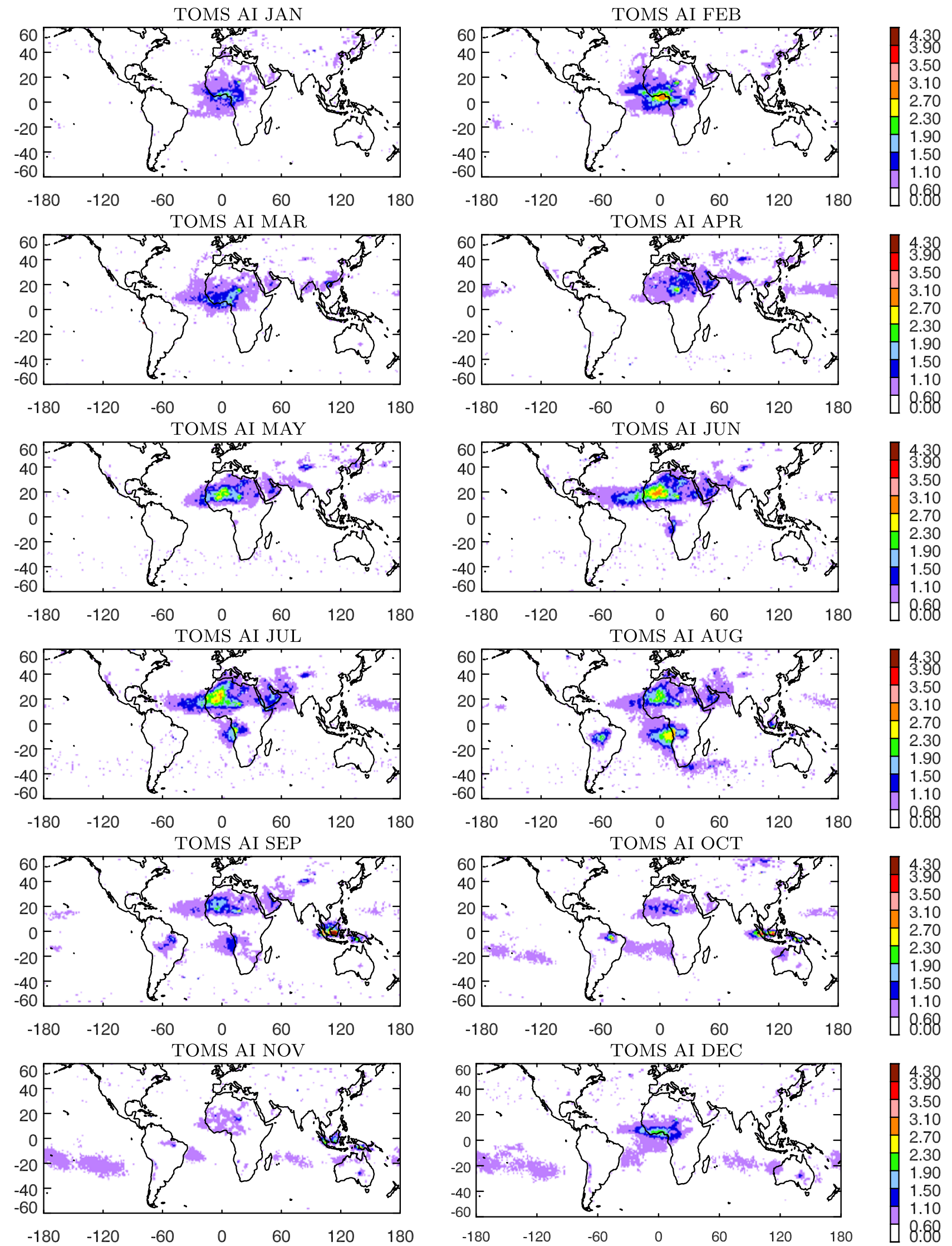

Figure 4. Monthly average of the EP TOMS AI in the year 1997. No cloud screening is applied to the daily TOMS AI. 

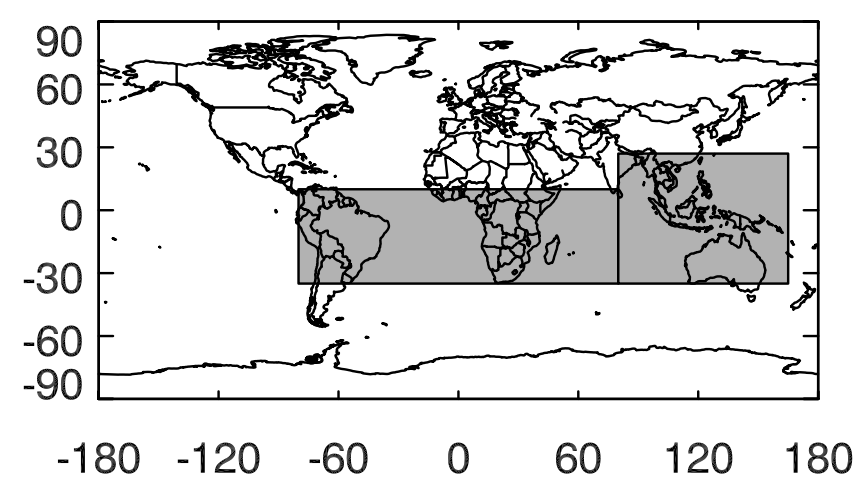

Figure 5. Preselected regions used in the inverse model. Further selections, i.e., that the observed AI $>0.4$ and that the reflectivity $<0.4$, are applied to these regions to generate the final set used in the inverse model.

the dust emissions. Two such regions are the Sahel and India. On the basis of the work reported by Penner et al. [2002], models suggest that the optical depth due to biomass smoke is about half of the total AOD during the burning season of January, February and March in the Sahelian region. Including data points south of $10^{\circ} \mathrm{N}$ in the inverse model produces reasonable a posteriori emissions. The modeled AI based on the a posteriori emissions is in the range of the observed AI. This probably indicates that dust aerosols are relatively well characterized, or that spatial patterns of biomass aerosols are well represented in this region. In India, biomass smoke contributes about half of the total AOD in January, February and March, but only one third in April. The modeled AI in March and April suggests that Northern India is largely affected by dust arriving from the west [see Herman et al., 1997, Figure 13]. Including the Northern India region in the inverse model results in a negative source strength in India. Therefore only data points in East India near the Bay of Bengal are included in the inverse model.

[47] There are large regions where the AI value is small (AI $\leq 0.4$ ), or the signal is due to dust aerosols. These regions should not be included in the inverse model, and hence are not included in the inversion procedure. In addition, TOMS AI in middle and high latitudes is not included in the inversion to avoid the data quality issues for TOMS when measurements were taken at large solar zenith angles [Herman et al., 1997; Hsu et al., 1999]. Figure 5 plots the preselected regions used here for inverse modeling. These regions contain most of the areas where there are biomass smoke signals in the TOMS AI plots and neglect those regions where signals are mainly due to dust aerosols. The AI signal in November and December over the southern Pacific between $10 \mathrm{~S}$ to $20 \mathrm{~S}$ is probably due to eastward transport of biomass smoke originating from Indonesia. Since no inversion is performed for biomass burning emissions in December, omitting these points probably will only affect the results for November.

\section{Results and Discussion}

[48] The six scenarios involved in the base calculation and sensitivity studies and their results are summarized in Table 2. Scenario SC1 represents the base scenario which was explained in sections 3 and 4. Scenario SC2 evaluates the effect of the a priori uncertainty on the a posteriori emissions. In scenario SC3, the calculated biomass aerosol concentrations from forest and savannah in $\mathrm{SC} 1$ are elevated by $1 \mathrm{~km}$, in order to test the effect of uncertainties in the aerosol vertical distribution. Scenario SC4 allows optimizing the biomass emissions in the rest of the world (region 7 in Figure 3). Scenario SC5 uses stricter cloud screening criteria where the monthly average TOMS AI and its standard deviation are calculated on the basis of data points with reflectivity less than $15 \%$. All the first five scenarios only include diagonal elements in the covariance matrix, while in the last scenario SC6, off-diagonal elements are also included.

[49] In all the scenarios the $\mathrm{BC} / \mathrm{OM}$ ratio is kept constant before and after optimization because of the fact that the $\mathrm{AI}$ is not sensitive to the pure scattering OM content in the smoke particles. The uncertainties associ-

Table 2. List of Scenarios Used in This Work and Resulting a Posteriori Emissions ${ }^{\mathrm{a}}$

\begin{tabular}{lllllll}
\hline & SC1 & SC2 & SC3 & SC4 & SC5 & SC6 \\
\hline A priori emission & L96 & L96 & L96 & L96 & L96 & L96 \\
A priori stdv, $\%$ & $50 \%$ & $100 \%$ & $50 \%$ & $50 \%$ & $50 \%$ & $50 \%$ \\
Optimizing region 7 & no & no & no & yes & no & no \\
Elevated aerosol, km & 0 & 0 & 1 & 0 & 0 & 0 \\
Cloud screening $\left(\mathrm{R}^{\mathrm{c}}\right)$ & $40 \%$ & $40 \%$ & $40 \%$ & $40 \%$ & $15 \%$ & $40 \%$ \\
Include covariance & no & no & no & no & no
\end{tabular}

Include covariance

Black Carbon Emissions

\begin{tabular}{|c|c|c|c|c|c|c|c|}
\hline \multirow{2}{*}{\multicolumn{8}{|c|}{ A Priori }} \\
\hline & & & & & & & \\
\hline Total & 5.58 & 6.31 & 6.87 & 5.68 & 6.07 & 5.88 & 6.37 \\
\hline NH & 2.96 & 3.26 & 3.43 & 3.13 & 3.01 & 3.15 & 3.25 \\
\hline $\mathrm{SH}$ & 2.62 & 3.05 & 3.45 & 2.55 & 3.06 & 2.72 & 3.12 \\
\hline \multicolumn{8}{|c|}{ Total Smoke Emissions } \\
\hline Total & 59.31 & 67.27 & 73.39 & 60.44 & 64.65 & 62.54 & 67.90 \\
\hline NH & 31.72 & 34.94 & 36.77 & 33.51 & 32.25 & 33.75 & 34.88 \\
\hline $\mathrm{SH}$ & 27.60 & 32.34 & 36.64 & 26.90 & 32.40 & 28.79 & 33.02 \\
\hline
\end{tabular}

${ }^{\mathrm{a}}$ Emissions are in $\mathrm{Tg} / \mathrm{yr}$. A priori emission L96 represents the biomass emissions from Liousse et al. [1996]. The annual emissions are for twelve months although the emission in December is unchanged because the inverse model is only applied from January to November 1997.

${ }^{\mathrm{b}}$ The a priori standard deviation values listed here are for monthly emissions in the six regions other than Indonesia, where the a priori standard deviation is assumed to be $200 \%$ for SC1, SC3, SC4, and SC5, and $300 \%$ for SC2.

${ }^{\mathrm{c}} \mathrm{R}$ is the critical reflectivity used to select "cloud-free" data points when the monthly mean AI is calculated. 
Table 3. Summary of a Priori and a Posteriori Emissions in $\mathrm{Tg} / \mathrm{yr}$ and Their Uncertainties $(1 \sigma)$ in Regions $1-7$ of Figure $5^{\mathrm{a}}$

\begin{tabular}{lcccccc}
\hline BC, Tg & Sahel & S. Africa & S. America & Indonesia & SE Asia \\
a priori $^{\text {b }}$ & $1.00 \pm 0.19$ & $0.65 \pm 0.14$ & $1.17 \pm 0.24$ & $0.22 \pm 0.14$ & $0.38 \pm 0.06$ & Australia \\
a priori $^{\text {c }}$ & $1.00 \pm 0.38$ & $0.65 \pm 0.28$ & $1.17 \pm 0.47$ & $0.22 \pm 0.21$ & $0.38 \pm 0.13$ & $0.33 \pm 0.08$ \\
a priori $^{\text {d }}$ & $1.00 \pm 0.19$ & $0.65 \pm 0.14$ & $1.17 \pm 0.24$ & $0.22 \pm 0.14$ & $0.38 \pm 0.06$ & $0.33 \pm 0.08$ \\
SC1 & $1.20 \pm 0.12$ & $0.68 \pm 0.04$ & $1.27 \pm 0.13$ & $0.65 \pm 0.52$ & $0.38 \pm 0.05$ & $0.28 \pm 0.06$ \\
SC2 & $1.32 \pm 0.24$ & $0.70 \pm 0.09$ & $1.44 \pm 0.22$ & $0.91 \pm 0.95$ & $0.40 \pm 0.11$ & $0.26 \pm 0.10$ \\
SC3 & $1.16 \pm 0.12$ & $0.62 \pm 0.04$ & $1.07 \pm 0.13$ & $0.34 \pm 0.22$ & $0.37 \pm 0.06$ \\
SC4 & $1.22 \pm 0.12$ & $0.68 \pm 0.04$ & $1.28 \pm 0.14$ & $0.65 \pm 0.52$ & $0.40 \pm 0.06$ & $0.26 \pm 0.06$ \\
SC5 & $1.12 \pm 0.12$ & $0.61 \pm 0.04$ & $1.07 \pm 0.13$ & $0.58 \pm 0.44$ & $0.38 \pm 0.06$ & $0.28 \pm 0.06$ \\
SC6 & $1.12 \pm 0.13$ & $0.56 \pm 0.05$ & $1.43 \pm 0.17$ & $0.66 \pm 0.63$ & $0.39 \pm 0.07$ & $0.28 \pm 0.06$ \\
\hline
\end{tabular}

${ }^{\mathrm{a}}$ The uncertainties are calculated assuming independent monthly uncertainties.

${ }^{\mathrm{b}}$ The a priori standard deviation values listed here are for Scenario SC1, SC3, SC4, SC6.

${ }^{\mathrm{c}}$ The a priori standard deviation values listed here are for Scenario SC2 only.

${ }^{\mathrm{d}}$ The a priori standard deviation values listed here are for Scenario SC4 only.

ated with the annual total emission for the a priori and a posteriori emissions are not listed in Table 2. Instead, we only list the uncertainties associated with the monthly a priori emissions in each region. The uncertainty of the total annual emissions can be deduced from the monthly uncertainty in each region, assuming that the uncertainty associated with each monthly source is independent of the other monthly sources. The deduced uncertainty associated with the a priori total annual emissions is about $6 \%$, which appears to be too low because of the assumption of independent monthly uncertainties in each region. Therefore we do not discuss the uncertainty associated with the annual total emissions. Instead, the uncertainties in the monthly emissions are discussed separately in the following subsections.

[50] The uncertainties associated with the a posteriori emissions and the breakdown of the a posteriori source strengths in each region will be discussed in the following subsections. The results are summarized in Table 3. The uncertainties associated with the annual emission in each region are calculated from the monthly uncertainties, assuming they are independent of each other. As mentioned in section 3 , this assumption may not be true. However, the values listed here give a general idea of how the uncertainties are changed before and after inverse modeling for the different scenarios. The assumption of independent monthly uncertainties does not change the relative magnitude of the a posteriori emissions in the different scenarios. The monthly uncertainties are given in the following subsections.

[51] The results of the base case are presented first, followed by the sensitivity scenarios. Previous studies using an inverse model indicate that results are also sensitive to the wind fields used [Hein et al., 1997; Bergamaschi et al., 2000a]. Since the observations in these studies are multiyear averages, these authors applied wind fields for different years in a sensitivity study. In this work, because the observational data are for a particular year (1997), climatological wind fields from a GCM or a year other than 1997 may not be appropriate for inverse modeling, although it would be interesting to see whether the use of the wind fields from a GCM would degrade the inverse modeling results. Such a study could be carried out if additional wind fields such as the NCEP fields for the year 1997 were available.
[52] A measure of the closeness of fit of the modeled AI and the observation is provided by the $\chi^{2}$ statistic which is defined as:

$$
\chi^{2}=\frac{(\mathbf{c}-\mathbf{h}(\mathbf{x}))^{\mathbf{T}} \mathbf{O}^{-1}(\mathbf{c}-\mathbf{h}(\mathbf{x}))}{n}
$$

where $\mathrm{n}$ is the total number of grid points involved in the inverse model. Higher $\chi^{2}$ indicates a larger deviation between the observations and the model results.

\subsection{SC1}

[53] The annual total average and regional a priori and a posteriori emissions are listed in Tables 2 and 3, respectively. Table 2 also lists the sensitivity scenarios examined here. The monthly emissions and their uncertainty for the base case, SC1, are plotted in Figure 6. The breakdown of monthly emissions in the first six regions for SC1 is plotted in Figure 7.

[54] The a posteriori annual biomass black carbon emission source strength in the base case is $6.31 \mathrm{Tg} / \mathrm{yr}$, which corresponds to an increase of $13 \%$ compared to the a priori annual emissions. The a posteriori monthly emissions are still in the uncertainty range of the a priori emissions. The total source strength uncertainty is calculated from the uncertainties associated with the emissions in each region, assuming independent regional uncertainties. The a posteriori uncertainties associated with the monthly emissions in

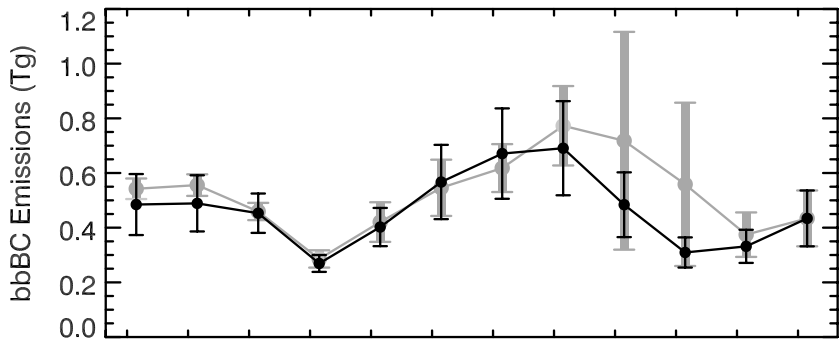

Jan Feb Mar Apr May Jun Jul Aug Sep Oct NovDec

Figure 6. Monthly a priori (solid line) and a posteriori (shaded line) BC emissions for SC1. The vertical lines represent the uncertainty range of the emission while the dots are the central values. 


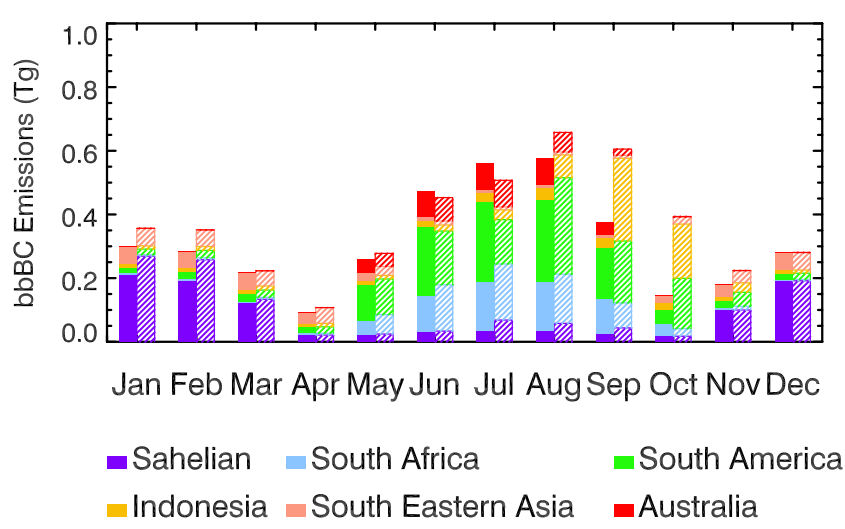

Figure 7. Monthly a priori (solid) and a posteriori (hatched) $\mathrm{BC}$ emissions for $\mathrm{SC} 1$ in the six regions defined in Figure 5. The color for each of the six regions is listed in the legends below the plot.

each region are plotted in Figure 8. The total source strength uncertainty is reduced substantially in January, February and March. In June, July, and August the reduction of the total source strength uncertainty is moderate, although the uncertainties in the two major biomass burning regions: South America and southern Africa, are reduced by about $80 \%$. However, the inverse model cannot constrain the biomass emissions in Australia and Indonesia. The increase in uncertainty in the total source strength in September and October is due to the increase of Indonesia emissions whose a priori uncertainty is assumed to be $200 \%$. The a posteriori emissions in Indonesia are about $35-50 \%$ of the total emission in the peak months of September, October and November, which results in a large uncertainty for the total emissions. To understand the how the inverse model performs and why it behaves in this way, the a posteriori emissions and their uncertainty in each month need to be examined.

[55] The slight increase of the total a posteriori emissions in January and February is due to the increase of the Sahelian biomass emissions. About $80 \%$ of the total biomass emissions come from the Sahelian region in the first two months of the year. In both of these two months, the model predicted AI is smaller than that from the TOMS AI (compare Figures 4 and 9). The high AI in the Sahelian region coincides with the biomass burning black carbon column burden maximum during this time. The model results with a posteriori biomass emissions exhibit some improvement in comparison with the TOMS AI, which can be evaluated through the $\chi^{2}$ statistic (Figure 8). However, the region with $\mathrm{AI} \geq 0.6$ is much more confined geographically than the observations (compare Figures 4 and 9). Increasing the a priori emissions in this region does not alleviate this problem in January, and probably indicates that the meridional flow in this region is too weak during this time, or that the aerosol removal is too fast. More over, during January and February, the absorbing aerosols seen in the observations are a mixture of dust and smoke aerosols, although the dust contamination in January is small [Herman et al., 1997]. As mentioned previously, the data points north of $10^{\circ} \mathrm{N}$ are excluded in the inverse model in order to lessen the contamination by dust. Including those points would further increase the a posteriori emissions. The a priori relative uncertainty of $50 \%$ in the Sahelian region is reduced tremendously to $5 \%$ in January and February, while the uncertainties in other regions remain unchanged. The reason is that the AI in the other parts of the world in both the model and the TOMS observations is small, and thus unable to constrain the biomass emissions there.

[56] The biomass burning season in the Sahel continues in March with a weaker source strength, while the burning in Southeast Asia increases. The inverse model overpredicts $\mathrm{AI}$ in most parts of Asia. From March through August, the modeled AI is larger than the observed AI over Sahara. Since dust emissions are not optimized in the inverse model, the overprediction in this region is associated with the dust source strength there, and indicates that the dust source strength is too strong. P. Ginoux (personal communication, 2002) suggested that because the soil moisture data for 1997 were actually for 1996, the dust emissions were not well known, which may explain part of the discrepancy. However, the overprediction in Northeast India near the Bay of Bengal is a combined effect of dust and smoke aerosols. The dust optical depth in Northeast India is about $50 \%$ of the total optical depth, and contributes about $75 \%$ to the AI. Restricting the inverse model in Asia to the region south of $25^{\circ} \mathrm{N}$ is necessary in order to minimizing the impact of dust. If the inverse model is thus restricted, the a posteriori emissions in Southeast Asia are reduced by $10 \%$ in March, and the relative uncertainty is reduced to $14 \%$, compared to the reduction of the a posteriori emissions to $83 \%$ of the a priori emissions and a relative uncertainty of $12 \%$ if the region North of $25^{\circ} \mathrm{N}$ is included. The comparison with the TOMS AI in biomass burning regions in Southeastern China degrades because of this reduction. Total emissions remain almost unchanged, because of the increase of the Sahelian emissions and the decrease of Southeast Asian emissions. In the base and other scenarios, we do not include the regions North of $25^{\circ} \mathrm{N}$.

[57] The burning season in South America starts in May in the a priori emissions and peaks in June, July, August and September, while the TOMS AI fails to detect any smoke aerosols (with AI $\geq 0.4$ ) until August. Accordingly, the

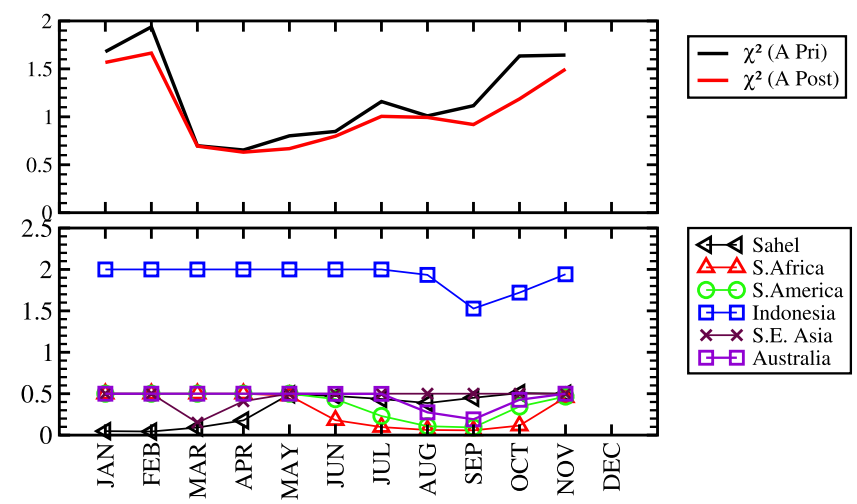

Figure 8. (top) The $\chi^{2}$ of the modeled AI with the a priori (black line) and posteriori (red line) emissions. (bottom) Uncertainties of the monthly a posteriori emissions in each of the six regions defined in Figure 3. The a priori uncertainties for the regions other than Indonesia are 50\%, while the a priori uncertainty in Indonesia is $200 \%$. Results are for $\mathrm{SC} 1$. 

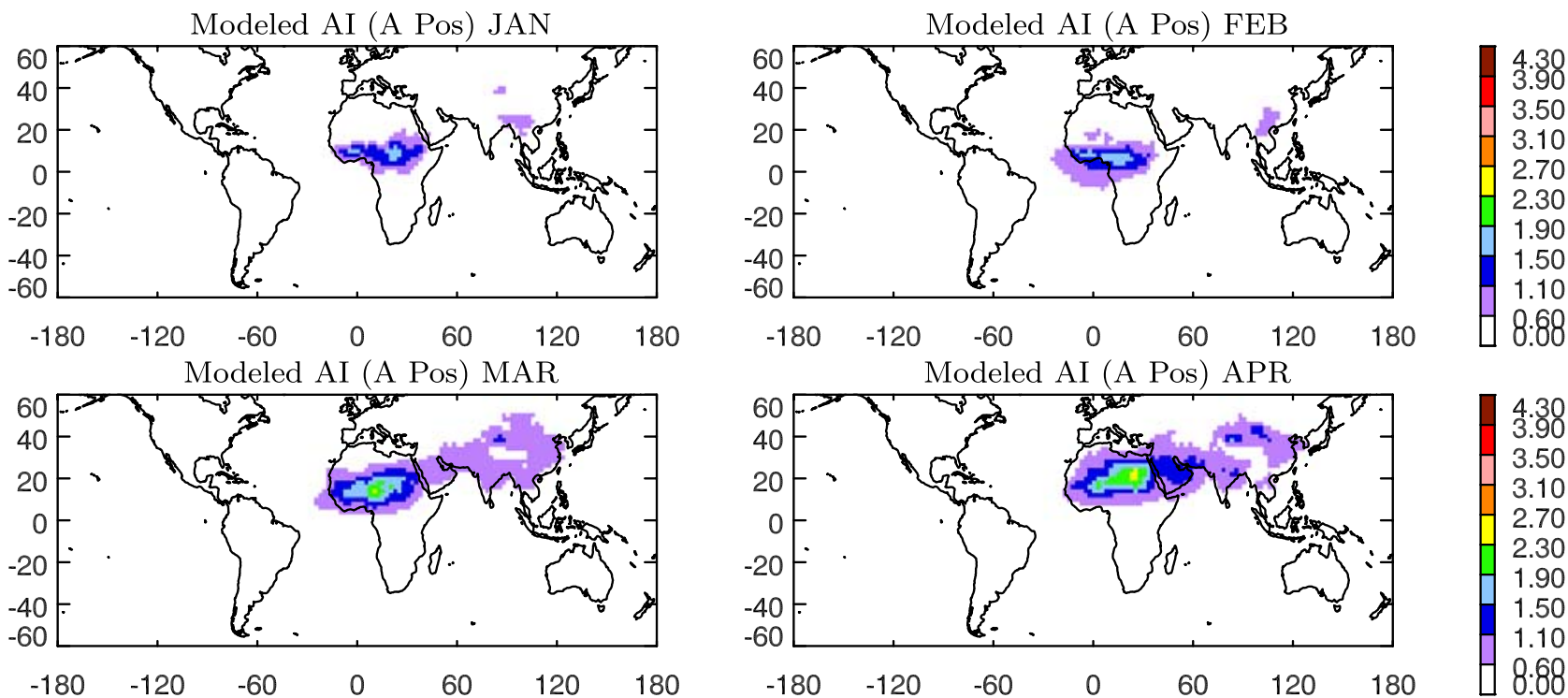

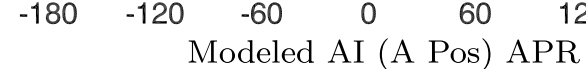
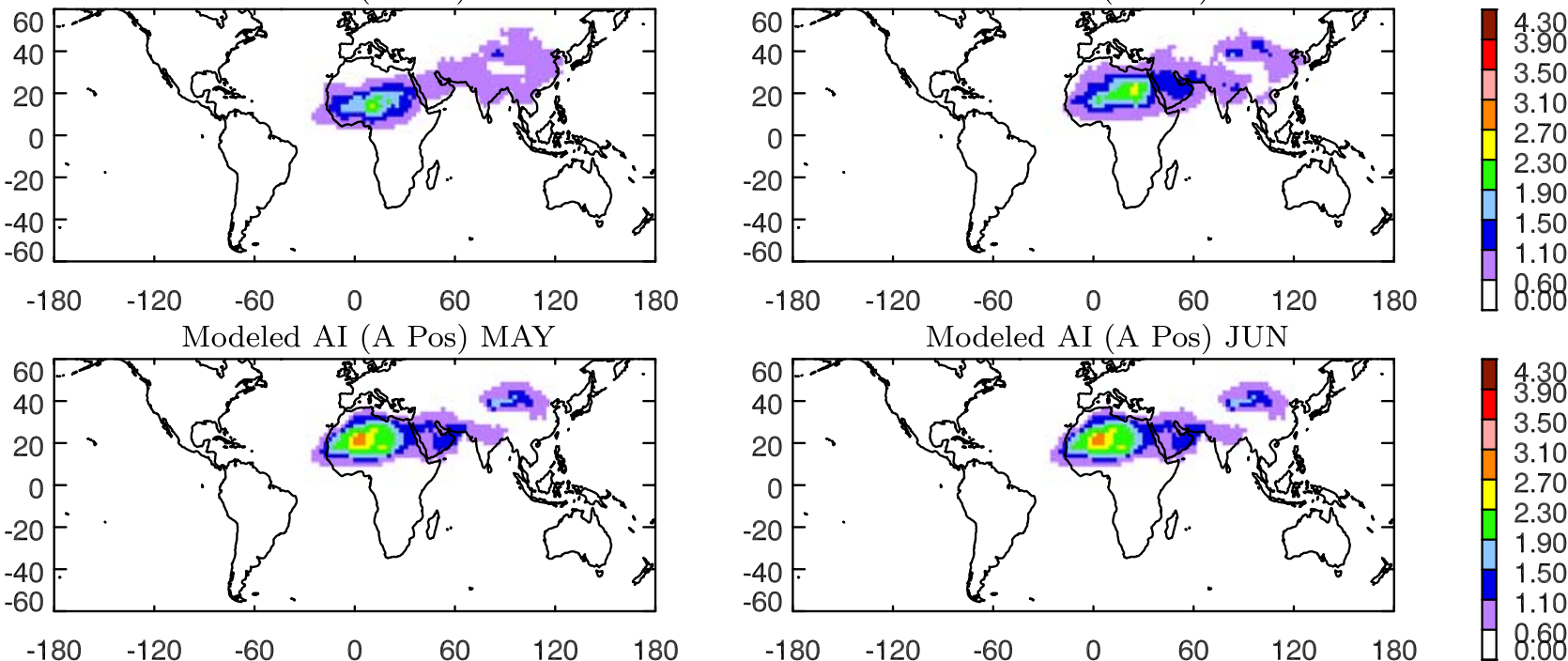

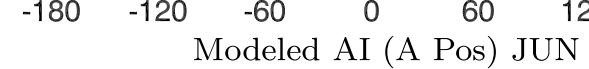
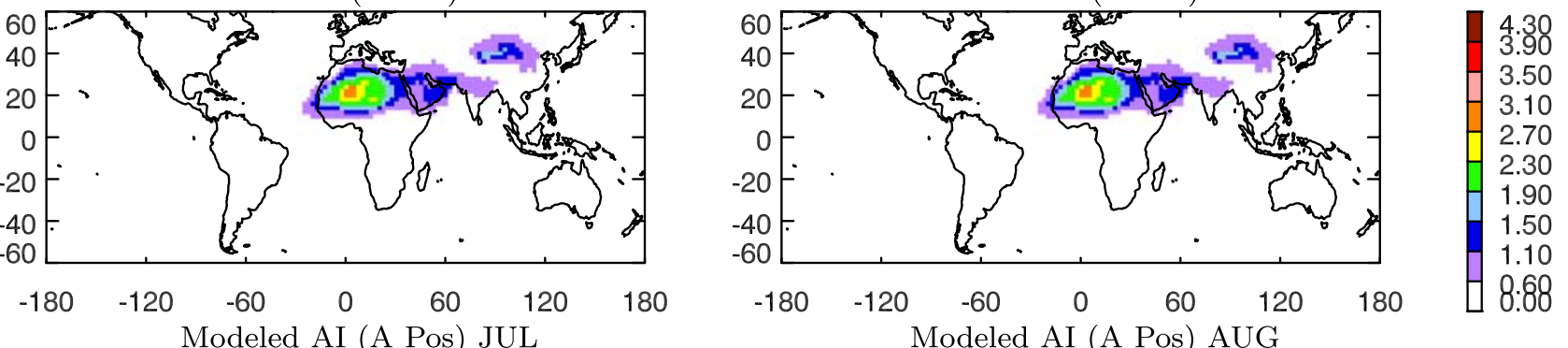

$$
\text { Modeled AI (A Pos) AUG }
$$
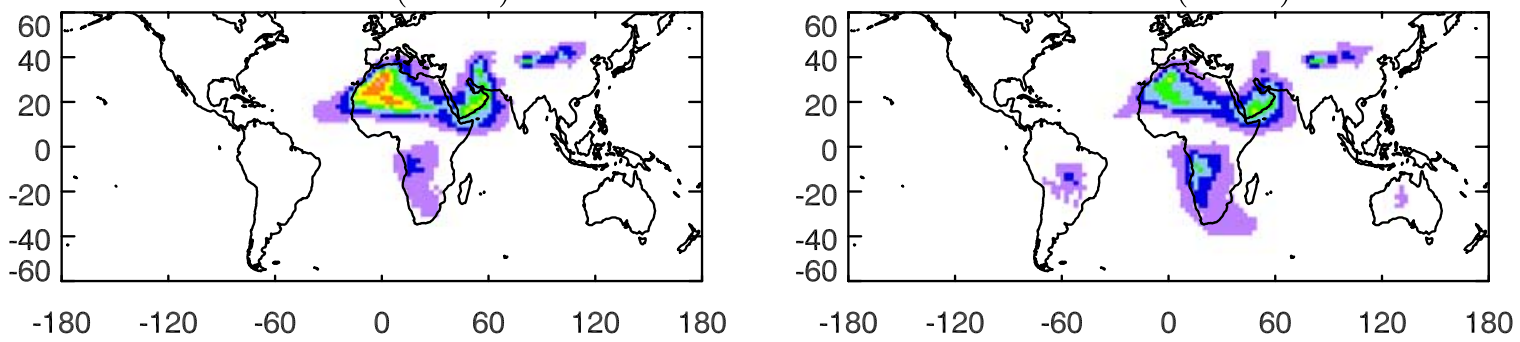

4.30
3.90
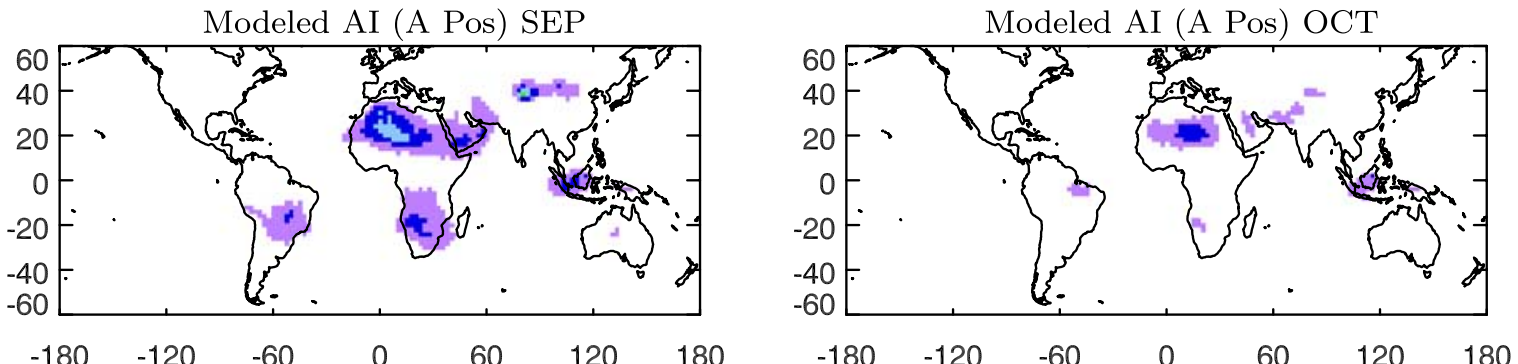

4.30
3.90 Modeled AI (A Pos) NOV
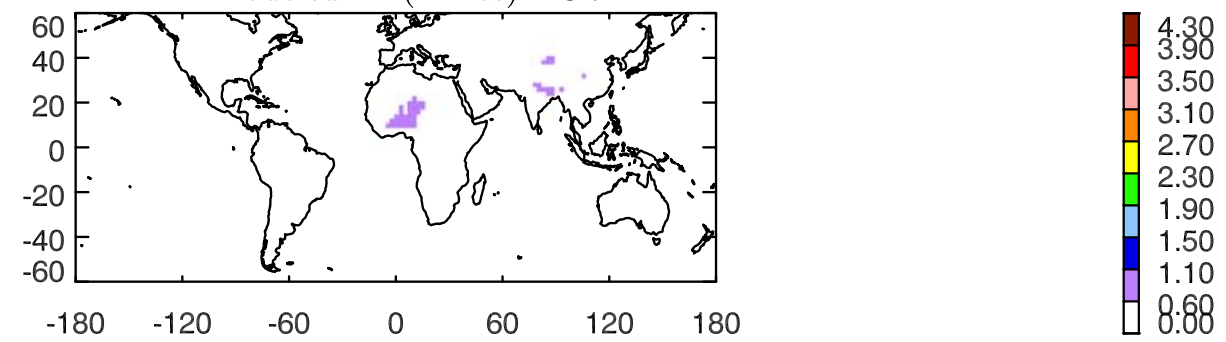

Figure 9. Monthly modeled AI with a posteriori emissions for SC1. 
biomass emissions in South America are reduced by $23 \%$, and $45 \%$ in June and July, respectively. On the other hand, southern Africa emissions are increased by $30 \%$ in June. As a result, the total emissions in June and July decrease. The comparison of the $\chi^{2}$ statistic of the a posteriori modeled AI with observations shows an improvement of $27 \%$ and $20 \%$ in June and July, compared to the a priori emissions, respectively. The uncertainties associated with southern Africa and South America emissions are both reduced by the inverse model, although the reduction in southern Africa is much larger.

[58] In August and September, the uncertainties in the biomass emissions in South America and South Africa are reduced with relative uncertainties of less than $10 \%$ for the a posteriori emissions. The biomass burning emissions in South America are increased by about $20 \%$ while those in southern Africa remain almost unchanged in August and are slightly decreased in September. Although the total amount of biomass burning in the four months (June to September) is only changed by a small amount, the seasonality in South America is changed considerably. The a priori emissions in South America have a smooth increase in June, July and August while the a posteriori emissions have a sharp increase in August compared to July. In southern Africa the a posteriori emissions peak in July, while the a priori emissions in southern Africa are almost the same in July and August. Therefore the most important change due to the inverse model in South America and southern Africa is the adjustment of the seasonality, while the adjustment to the total annual average emissions is relatively small.

[59] The a priori emissions by Liousse et al. [1996] were based the work by Hao et al. [1990] with improved emission factors. Hao et al. [1990] prescribe 6-month burning periods for their databases based on rainfall data and distribute a percentage of biomass burned in each month according to the distribution of surface ozone concentration observed at three African sites and two South American sites. The AERONET Sun photometer measurements suggest that the smoke aerosols from South American forest fires have a short seasonal duration compared to those from African savannah burning [Hsu et al., 1999], consistent with the a posteriori emissions estimated here. Galanter et al. [2000] constructed biomass burning emissions based largely on the work of Richardson [1994] and Hao and Liu [1994], with monthly fractions of biomass burning altered on the basis of the AVHRR [Malinggreau et al., 1989] and TOMS [Herman et al., 1997] satellite observations. Their seasonality of biomass emissions in South America is more consistent with the a posteriori emissions estimated here than with the a priori emissions in that the ratio of biomass emissions in July, August and September is 1:2:2 in the work by Galanter et al. [2000], while these ratios are 1:1:0.6 and 1:2.1:1.5 in the a priori emissions and a posteriori emissions estimated here, respectively.

[60] Duncan et al. [2003b] estimated the seasonal and interannual variation of biomass burning emissions using the fire count data from Along Track Scanning Radiometer (ASTR) and data from the AVHRR World Fire Atlas. The TOMS AI was used as a surrogate to estimate interannual variability in biomass burning in their study. Their results indicate that biomass burning in South America starts in July and generally peaks in August and September, consistent with the peak month of August in the a posteriori emissions in South America. In southern Africa, the peak burning starts in July because of biomass burning in southwestern Africa, and then has a stronger peak in September due to biomass burning in southeast Africa in Duncan et al. [2003b]. The a posteriori emissions in southern Africa successfully capture the early peak in July but fail to predict the late burning in September and October shown in Duncan et al. [2003b]. This difference is associated with the inconsistencies between the ATSR fire count data and the TOMS AI in the late burning season in southeast Africa [Duncan et al., 2003b].

[61] Together, the biomass burning emissions in South America and southern Africa in the four months from June to September constitute about $70-80 \%$ of the total emissions in these four months. In addition to the adjustment in these two regions, biomass burning in the other four regions is also adjusted. The emissions in Australia remain almost unchanged in June and July. Biomass burning emissions in September are decreased since the model AI is larger than the TOMS AI. The relative uncertainty of the Australian emissions is reduced from 50\% to about $27 \%$ in August and 18\% in September. The emissions in the Sahel are increased in July, August, and September. However, the corresponding uncertainties are only reduced by a small amount, compared to the a priori uncertainties. The increase in the a posteriori emissions may reflect the fact that the a priori Sahelian biomass emissions are too weak in these three months, or the increase may be the result of dust contamination due to the large Saharan dust source.

[62] The South American emissions are increased by a factor 3.6 in October and by a factor of 2 in November. Additional smoke is observed by the TOMS AI in October and November in the region around the mouth of the Amazon River (Figure 4). Biomass burning in this region is usually due to agricultural activities [Setzer and Pereira, 1991]. The October biomass smoke signal in this region is stronger in 1997 than for any other months in the available EP TOMS operational period. Therefore a smaller increase of biomass emissions is expected for these months in years other than 1997.

[63] The modeled uncertainty is reduced in South America because of the use of the TOMS AI. In addition, the seasonality of South American Emissions is adjusted according to the TOMS AI in 1997. The a posteriori emissions are reduced by $45 \%$ in July because the TOMS AI was very small, less than 0.6 for most regions in South America. The small TOMS AI value in South America may indicate little fire activity in July. However, it is possible that TOMS AI cannot detect the fires because of the fact that biomass smoke is not transported high enough, or that the smoke is scavenged out. Additional comparison with emission data sets in 1997 that do not use the TOMS AI information is needed to evaluate how realistic the adjustment in our analysis is. Furthermore, the seasonality of 1997 may not be representative of the decadal average.

[64] The most substantial change in the a posteriori emissions is in Indonesia where the annual emissions are increased by a factor of 3 to an annual emission source 
strength of $0.65 \mathrm{Tg} / \mathrm{yr}$. The increase in the two peak months of September and October is around a factor of 8 . The comparison of the modeled AI from the a posteriori emissions and the TOMS AI indicates that the model still underestimates biomass emissions in Indonesia considerably. Page et al. [2002] estimated the total amount of carbon released from peat and forest fires in Indonesia during 1997 using satellite images of a 2.5 million hectare area in Central Kalimantan. They used Landsat TM/ETM (enhanced thematic mapper) images and field observations to determine the biomass type and fraction of area covered by each biomass type. Both Synthetic Aperture Radar (SAR) and Landsat TM/ETM were employed to determine the burned area. By extrapolating the results from Central Kalimantan to the entire Indonesian region, they estimated that the total carbon released from the fire in 1997 was between 0.81 and $2.57 \mathrm{Gt} \mathrm{C}$.

[65] The emission factor for tropical forest is $0.66 \pm$ $0.31 \mathrm{~g} \mathrm{BC} /$ dry mass burned [Andreae and Merlet, 2001]. If $50 \%$ percent of the burned dry matter is carbon [Hély et al., 2003; Scholes and Andreae, 2000], then the total BC emissions corresponding to the estimates by Page et al. [2002] are between 0.57 and $5.0 \mathrm{Tg}$. The a posteriori BC emissions we estimate are only $0.65 \mathrm{Tg}$ and are in the lower end of this range. Duncan et al. [2003b] estimated BC emissions for September, October and November 1997 in Indonesia of $2.6 \mathrm{Tg}$, and $\mathrm{BC}+\mathrm{OM}$ emissions of $21.1 \mathrm{Tg}$. The total carbon released during the fire was estimated to be $700 \mathrm{Tg}$, less than the range given by Page et al. [2002]. Thus it appears that the assumed $\mathrm{BC}$ emission factor in the work by Duncan et al. [2003b] is about $1.86 \mathrm{~g} / \mathrm{kg}$. If the BC emission factor had been the value in the work by Andreae and Merlet [2001], the $\mathrm{BC}$ emissions would be $0.92 \mathrm{Tg}$ for these three months which is closer to our estimate. Levine [1999] estimated that the total particle mass (TPM) release during the Indonesia fire in 1997 was about 8.2 to $24.9 \mathrm{Tg}$ C, with a best estimate of $16.6 \mathrm{Tg}$ C. About $94 \%$ of this estimate was from peat burning. The ratio of carbon to TPM is about 0.6 [Ward et al., 1991]. Therefore the best estimate of TPM emission is about $27.7 \mathrm{Tg}$ in the work by Levine [1999]. The total carbon $\left(\mathrm{CO}_{2}+\mathrm{CO}+\mathrm{CH}_{4}+\mathrm{TPM}\right)$ is 242.7 Tg in the work by Levine [1999], much less than that in the work by Duncan et al. [2003b], but the BC+OM emission is similar (27.7 versus $21.1 \mathrm{Tg}$ ). The a posteriori TPM emission estimated here is 6.9, about a quarter of what was estimated by Levine [1999]. However, if most of the TPM emissions came from peat burning as estimated by Levine [1999], the smoke aerosols would tend to reside in the boundary layer and would not have been detected by TOMS. This could be the main reason that our estimates are smaller than most of these other studies (see, however, section 5.2).

[66] The $\chi^{2}$ is calculated to evaluate how well the a posteriori emissions perform in general. An examination of the $\chi^{2}$ of the a priori and a posteriori emissions shows a moderate to small improvement using the a posteriori emissions, probably indicating the limitation of the inverse model. The modeled AI using the forward model has a different small-scale distribution from that of the TOMS AI, although the geographic location and distribution over larger scales usually agrees with the TOMS AI. Two possible reasons for this discrepancy are (1) the geographic distribution of biomass burning emissions in the preassigned subregions is not accurate, so that optimizing biomass burning emissions on a smaller spatial scale is needed, and (2) the transport model has difficulty in reproducing small-scale features because of uncertainties in the horizontal and vertical transport, in wet and dry deposition, and in the geographic distribution of the a priori emissions. It is the inability of the forward model to accurately reproduce the small-scale geographic variation in AI that limits the capability of the inverse model to further reduce the $\chi^{2}$ between the modeled and TOMS AI.

\section{2. $\mathrm{SC} 2$}

[67] The comparison of the modeled AI based on the posteriori emission with the TOMS AI in Indonesia (Figure 4 versus Figure 9) for the base case scenario indicates that the modeled AI is too small in Indonesia, suggesting that a further increase of the a posteriori emissions in $\mathrm{SC} 1$ is needed. A possible reason is that small a priori uncertainty restricts the model capability to adjust the a priori emissions in order to follow the observations. The underestimation of the a posteriori emission in Indonesia probably suggests that the assumed uncertainty for Indonesia in scenario $\mathrm{SC} 1$ is too small. Therefore the uncertainty $(1 \sigma)$ of biomass burning emissions in Indonesia was increased to $300 \%$ in scenario SC2. The assumed a priori uncertainty in other regions may also affect the corresponding a posteriori emissions.

[68] In SC2 the uncertainty of the a priori emissions is increased to $300 \%$ in Indonesia and to $100 \%$ elsewhere. The a posteriori emissions and their breakdown into difference regions are listed in Tables 2 and 3, respectively. The annual $\mathrm{BC}$ emissions in $\mathrm{SC} 2$ are $6.87 \mathrm{Tg} / \mathrm{yr}$, an increase of $23 \%$ compared to the a priori emissions and an increase of $9 \%$ over the results of $\mathrm{SC}$. Increasing the a priori uncertainty allows the inverse model to adjust the a priori emissions to a greater extent. This is expected, since the least squares of the a priori and a posteriori emissions are weighted by the reciprocals of the square of the a priori error. Therefore the second term in equation (5) is decreased. The net effect of increasing the a priori uncertainty in this case is to increase the a posteriori emissions. In the first five regions, both $\mathrm{SC} 1$ and $\mathrm{SC} 2$ have larger a posteriori emissions than the a priori emissions, with the annual a posteriori emissions in $\mathrm{SC} 2$ even larger than those in SC1. The emissions in Australia (region 6), on the other hand, are slightly smaller than those estimated in $\mathrm{SC} 1$.

[69] The difference between the annual emissions in SC1 and SC2 is small in southern Africa, Southeast Asia and Australia although the May emissions in SC2 in South Africa are increased by more than a factor of 2 compared to SC1. In May, the southern African emissions are increased in order to match the biomass burning signal in the TOMS AI. The increase is more drastic in SC2, about a factor of 2, compared to the $40 \%$ increase in SC1. The a posteriori $\chi^{2}$ is smaller in SC2 than in SC1, indicating that the adjustment in $\mathrm{SC} 2$ improves the agreement between the TOMS and the modeled AI. The difference in the Sahel and South America is moderate in June and July. The decrease of the South American sources is larger in $\mathrm{SC} 2$ than in $\mathrm{SC} 1$, about $40-50 \%$, while the difference in Indonesia is $40 \%$. The uncertainty of the a posteriori emissions in each region 

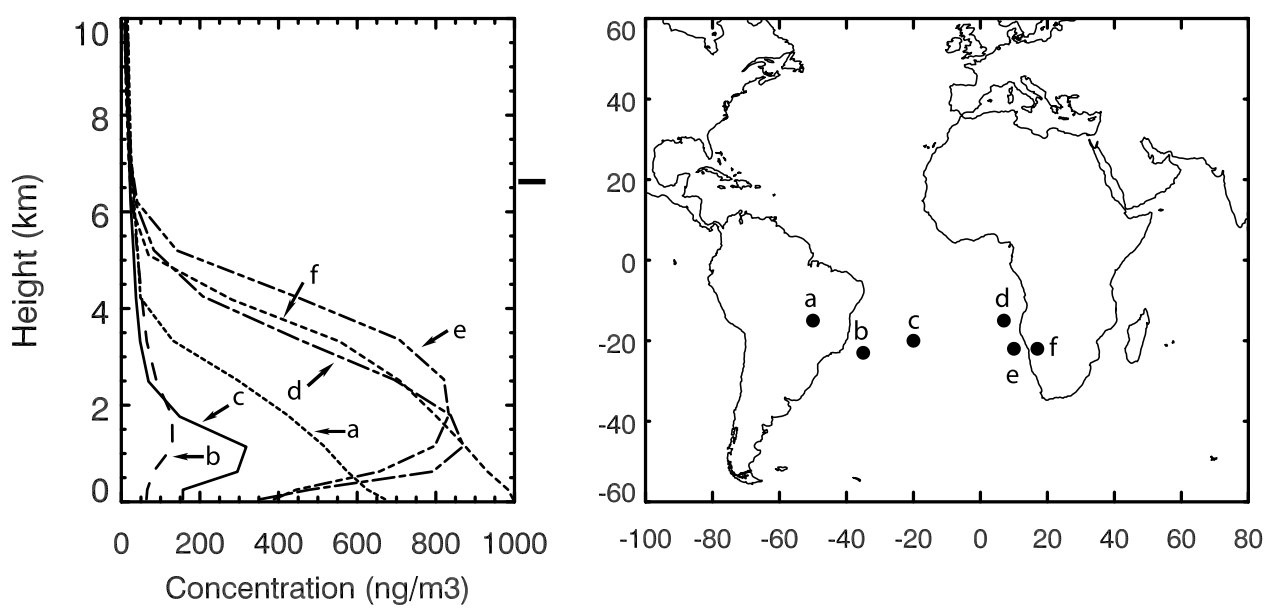

Figure 10. (left) Vertical distribution of biomass black carbon at various locations in September 1997. (right) Locations.

increases as a result of the larger a priori uncertainty. The increase in the a posteriori uncertainty is almost proportional to the assumed a priori uncertainty because of the linear propagation of the a priori uncertainty to the a posteriori uncertainty.

[70] The decrease of the Australian source in June is rather accidental since there is no indication of overestimation by comparing the modeled AI based on the a priori emissions and the TOMS AI. The $\chi^{2}$ and a posteriori uncertainty is decreased to a larger extent in July than in June because more observation data are included in the inverse model in July, especially in South America.

[71] In August, September and October, the increase of South America emissions ranges from $40 \%$ in August to $400 \%$ in October, which is an increase of $0.27 \mathrm{Tg}$ from the a priori emissions and $0.17 \mathrm{Tg}$ from the result of $\mathrm{SC} 1$.The largest difference between the $\mathrm{SC} 1$ and $\mathrm{SC} 2$ is the a posteriori emissions in Indonesia, where $\mathrm{SC} 2$ results in the annual emission source strength of $0.91 \mathrm{Tg}$, about $40 \%$ higher than $\mathrm{SC} 1$. The increase of the a priori emissions in September and October is a factor of 11. Both the a posteriori $\chi^{2}$ and the uncertainty are reduced. Comparing the result of $\mathrm{SC} 1$ and $\mathrm{SC} 2$, the uncertainty of emissions in Indonesia is reduced by a relatively larger extent in $\mathrm{SC} 2$, indicating that the original assumed uncertainty of $200 \%$ is too small. Larger a priori uncertainties also result in a posteriori emissions for Indonesian fires that are closer to the estimation of Page et al. [2002], Duncan et al. [2003b], and Levine [1999] (see text in section 5.1). However, the estimated emissions for Indonesia are still lower than previous estimates, probably because the smoke from peat burning is not detected by TOMS. The magnitude of the underestimation is difficult to quantify without further information about the contribution of peat burning to the total emissions from this region.

[72] The results from two scenarios, $\mathrm{SC} 1$ and $\mathrm{SC} 2$, suggest that it is very important to estimate an accurate a priori uncertainty. An underestimate of the a priori uncertainty does not allow the inverse model to adequately fit the observations since the a posteriori emissions are very sensitive to the assumed a priori uncertainty. On the other hand, if the a priori uncertainty is not the limiting factor, the a posteriori results are not as sensitive to the assumed uncertainty.

\section{3. $\mathrm{SC} 3$}

[73] Case SC3 examines the sensitivity of the a posteriori emissions to the aerosol vertical distribution. Figure 10 shows the vertical distribution of biomass black carbon calculated by the model at various locations. Over continents, the biomass smoke layer is relatively well mixed, extending between the surface and $4 \mathrm{~km}$ in the model, while over the oceans, the smoke concentrations are between 0.5 and $3.5 \mathrm{~km}$ and peak between 1 and $2 \mathrm{~km}$. Field campaign results during the TRACE A period indicated that peak biomass aerosols were found near $1.5-2.0 \mathrm{~km}$ in the source regions, and between 1.5 and $4 . \mathrm{km}$ over the ocean in the outflow region from the continent [Anderson et al., 1996; Fuelberg et al., 1996; Browell et al., 1996]. Haywood et al. [2003] measured the biomass aerosol concentration profiles during SAFARI 2000. Their results also appeared to have a more elevated aerosol layer over ocean. The aerosol layer in the model seems to be slightly lower than in the observations. However, since the observations took place during the day when the vertical mixing was the strongest, the difference may partly be due to the fact that monthly mean concentrations are plotted for the model, which average through both the day and the night.

[74] The fact that biomass burning smoke is found to peak at levels above the surface near the sources is probably due to the local convection and buoyancy developed by large fires. It should be noted that in all the scenarios except SC3, biomass smoke from savannah and forest fires and biofuel burning is injected at the surface in the model. There is no treatment to account for the effect of large fires and the local buoyancy due to these fires. To evaluate the effect of any possible bias, in scenario SC3, biomass burning aerosols due to savannah and forest fires are lifted by $1 \mathrm{~km}$, while the vertical distribution for other smoke aerosols remains unchanged. This increases the modeled AI over the major biomass burning areas, which leads to smaller a posteriori emissions in $\mathrm{SC} 3$ than other scenarios.

[75] The total annual a posteriori emission source strength in $\mathrm{SC} 3$ is $5.68 \mathrm{Tg} / \mathrm{yr}$, only a slight increase over the a priori 
emissions. The cancellation of the decrease of emissions from South America in June, July and August and the increase of emissions from Indonesia leads to a relatively small adjustment to the total annual emissions. In SC1 and SC3, the emissions in the Sahel are increased during January, February, and March, although SC3 has a smaller increase. In other regions, the direction of adjustment (increase or decrease) is also consistent in SC1 and SC3, indicating that the difference between the a priori $\mathrm{AI}$ and modeled AI cannot be readily explained by increasing the aerosol height from large fires. The adjustment of the a priori emissions is necessary, although there may be an overestimation of the a posteriori emissions in scenario SC1 since there is no special treatment for biomass burning aerosols due to large fires in SC1.

[76] The comparison of the modeled AOD and AI slope with the observed slope indicates that model agrees well with the observations (section 2.2). Increasing the height of biomass smoke aerosols due to forest and savannah fires by $1 \mathrm{~km}$ decreases the AOD-AI slope to 0.93 and 0.44 in South America and in southern Africa, respectively. Since the AOD-AI slope is affected by the aerosol optical properties and aerosol height, this suggests that lifting biomass smoke aerosols due to large fires by $1 \mathrm{~km}$ probably causes an overestimation of the aerosol height. Therefore the results of SC1 and SC3 probably provide an upper and lower limit for the inverse model because of the change of aerosol vertical distribution.

\section{4. $\mathrm{SC} 4$}

[77] The only difference between scenario SC1 and SC4 is that SC4 allows an optimization of the source in region 7 (the rest of the world), while SC1 keeps the source in region 7 fixed in the inverse model. Because the a priori emissions do not include the temperate and boreal emissions, the emissions in these grid boxes are zero. In all of our analysis, TOMS AI at high latitudes is not included because of data quality issues in these regions (see section 4). The difference in the total annual BC emissions between SC4 and $\mathrm{SC} 1$ is $0.24 \mathrm{Tg}$. The annual emissions in the first six regions remain almost unchanged, while the emissions in region 7 decrease by about $0.28 \mathrm{Tg}$ compared to SC1.

[78] EPA reported air pollutant emission data from 1970 to 2002 by sector on the annual average basis. Unfortunately, the emissions due to forest wildfires and slash/prescribed burning are not available for 1997. Since only PM2.5 and PM10 emissions were reported, we use the emission factor from a report that EPA supported (W. Battye et al., unpublished report) to convert the PM2.5 to BC emissions. The total annual $\mathrm{BC}$ emissions are $0.059 \mathrm{Tg}$ compared $0.045 \mathrm{Tg}$ in the a priori emissions and $0.040 \mathrm{Tg}$ in the a posteriori emissions. The underestimation is partly due to the fact that observational points in the US are not included in the inverse model (see the discussion below). In addition, using a separate source region for North America will improve the a posteriori emissions.

[79] The decrease of the annual emissions in region 7 including the United States in scenario SC4 mostly comes from the decrease in February, March, and April. This is due to the slightly larger emissions in the Sahel in SC4 compared to those in $\mathrm{SCl}$ during those months. The inverse model increases the emissions in region 7 and decreases the emissions in the Sahel in order to fit the observations. Since the emissions from region 7 generally have a weaker concentration response for those points considered in the inverse model, the small increase (about 1\%) in the Sahel causes a relatively large decrease in region 7. Similarly, in March and April, the decrease in emissions in region 7 is due to a slight increase in emissions in Southeast Asia. This implies a potential insufficient number of data points in the inverse model with respect to the region 7 in SC4. For example, Central America is part of the region 7. While the model allows the adjustment of the source in region 7 in $\mathrm{SC} 4$, the observed TOMS AI is less than the cutoff value of 0.4 in region 7 and nearby regions, because of relatively weak biomass burning and perhaps lower-biomass aerosol layers. The contrast between the large response of the emissions in regions $1-6$ and the small response of the AI in region 7 leads to a relatively large adjustment of the emissions in region 7 in some cases.

[80] The $\chi^{2}$ for SC4 is close to the result in SC1, except in April, when it is only 0.37 compared to the value of 0.63 in $\mathrm{SC} 1$, because of the large decrease of the emissions in region 7. The comparison of the a priori modeled AI and TOMS AI in April indicates an underestimation of AI in SC1 in Southeast China and Indochina and an overestimation near the Bay of Bengal. Increasing the emissions in Southeast Asia and decreasing those from region 7 (mainly to decrease the emissions in India) leads to a better agreement with the observation.

[81] The uncertainty of the emissions in region 7 is decreased in March and April and remains almost unchanged in other months, indicating that the observations are insufficient to reduce the uncertainty of the emissions in region 7. This is probably due to the use of the criteria $\mathrm{AI} \geq$ 0.4 , causing less observational points to be included in the inverse model to constrain biomass burning emissions in region 7 .

\subsection{SC5}

[82] The purpose of scenario SC5 is to assess the uncertainty due to cloud screening. In this case a more rigid cloud screening criterion is applied, which results in a smaller monthly average TOMS AI for the data points satisfying this criterion (section 4). The two reasons for examining a higher threshold for cloud screening, as mentioned in section 4, are (1) using only reflectivity data fails to discriminate between clouds and aerosols and (2) the AI is larger when biomass smoke aerosols are above cloud.

[83] Figure 11 shows the modeled AI for aerosols above and below the cloud. When biomass smoke is above the cloud, the modeled AI is increased by about $20 \%$, because of the fact that aerosol absorption is enhanced. The increase becomes larger when the cloud optical depth increases. On the other hand, AI is decreased by $60-80 \%$ when the aerosol is below the cloud. When the cloud optical depth reaches 25 , the modeled $\mathrm{AI}$ is only about $20 \%$ of the cloudfree value. Therefore the effect of clouds on AI depends on the vertical distribution of the aerosols and the clouds. The aircraft measurements during the SAFARI 2000 campaign indicated that the aerosol concentration was well mixed vertically through $500 \mathrm{mb}$ over land, while over ocean the aerosol layer was between 850 to $500 \mathrm{mb}$, which was above the stratocumulus clouds near $950 \mathrm{mb}$ [Haywood et al., 


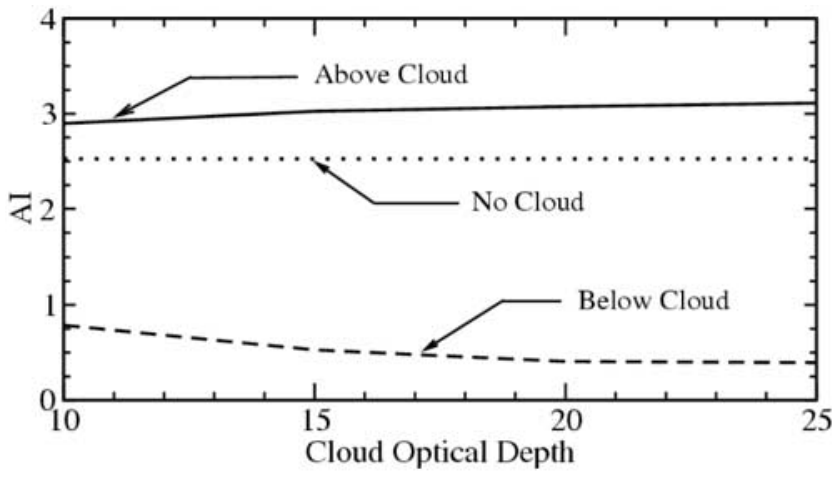

Figure 11. Sensitivity of AI to biomass aerosols above and below the cloud, assuming the BC fraction is $10 \%$ of the total mass and the aerosol optical depth is equal to 2 . The aerosol size distribution is listed in Table 1. The solar zenith angle is equal to 40 degrees. The surface reflectivity is 0.06 . The mean altitude of the aerosol layer is $3 \mathrm{~km}$ in all cases. The cloud is in the layer between 1 and $2.5 \mathrm{~km}$ in the case where the aerosol is above the cloud and is in the layer between 4 and $5.5 \mathrm{~km}$ in the case where the aerosol is below the cloud. In addition, the cloud optical thickness is set to the same value at both 331 and $360 \mathrm{~nm}$.

2003]. Therefore the AI is probably larger than it would be in cloud free regions over the ocean due underlying cloud while the change in AI due to clouds over land is hard to determine. Using a reflectivity of less than or equal to $15 \%$ to select cloud free regions results in a monthly average AI with virtually no data points exceeding 1.5 (not shown here).

[84] The annual biomass black carbon emissions in SC5 is $5.88 \mathrm{Tg} / \mathrm{yr}, 0.4 \mathrm{Tg}$ less than those in SC1 where the cloud screening reflectivity is $40 \%$. The monthly emissions and uncertainty are very similar to those in SC1, although the monthly emissions in SC5 are somewhat smaller. The largest change is in South America, where emissions are reduced from June to September but increased by a large amount in October. The annual a posteriori emission in South America is almost the same as the a priori emission. The annual emission source strength in Indonesia is $0.58 \mathrm{Tg} / \mathrm{yr}$, a large increase of the a priori emissions of $0.22 \mathrm{Tg} / \mathrm{yr}$ there, but slightly smaller than the result for $\mathrm{SC} 1$. The difference between the a posteriori emission in SC5 and SC1 is about $10 \%$ in the Sahel, southern Africa and Indonesia, while it is about $17 \%$ in South America. Emissions in Southeast Asia and Australia are almost the same in SC5 as in SC1.

[85] The adjustment in the a posteriori emissions indicates that cloud screening cannot explain the discrepancy between the model and the observations. However, the difference between emissions in SC5 and those in SC1 is smaller than the difference of the monthly mean TOMS AI in the two scenarios, partly because of the fact that the locations with larger monthly mean TOMS AI values in SC1 are associated with large daily standard deviations since the daily variation is large near the source regions. Therefore the a posteriori emissions are less sensitive to the AI value of these points.

[86] The cloud screening does not appear to have much effect on the a posteriori uncertainty, which is almost the same in $\mathrm{SC} 1$ and $\mathrm{SC} 5$ in each region. The decrease of the a priori $\chi^{2}$ is also similar in SC1 and SC5, although the a priori $\chi^{2}$ is different in the two scenarios because of different monthly mean TOMS AI. Therefore cloud screening seems to have a relatively small effect on the inverse model results.

\subsection{SC6}

[87] In the first five scenarios, the covariance matrix is assumed diagonal, i.e., the error of each location is independent. Since the error of adjacent locations is dependent, the purpose of scenario SC6 is to test the sensitivity of this assumption. However, there are some issues with how the covariance is calculated. When launched in July 1996, the EP TOMS initially had a lower orbit of $500 \mathrm{~km}$. In December 1997 it was elevated to an altitude of $739 \mathrm{~km}$. Because of the lower orbit in 1997, the daily coverage was only $60 \%$ of the Earth's surface in the tropics, where major biomass burning occurs. The covariance of two locations is calculated for the period when the EP TOMS data are available at both locations. In the tropics, the number of valid days per month for any two locations is frequently less than 10. The small sample set in the calculation introduces a large bias to the real covariance between two locations. Since the overlapping set is calculated separately for each pair of locations, each different pair of locations have different overlapping sets, and the size of the set is always smaller than what is used to calculate the standard deviation. As a result, the covariance matrix computed here is an approximation of the "true" covariance matrix, where all covariances are obtained from the same set of observations. To ensure that the covariance matrix $\mathbf{O}$ is nonnegative definite, meaning $\mathbf{X}^{\mathbf{T}} \mathbf{O X} \geq 0$, where $\mathbf{X}$ is an arbitrary vector, a smaller set of locations for the calculation of the covariance matrix are selected. The size of the data set is reduced by at least $70 \%$ in general for this procedure. However, since the size of the data set before reduction is around 1000 for each month, this left a data set with about 100-300 elements for each month, which is still large enough to carry out an inversion. The inverse model results in SC6 are based on the reduced data set generated from the original set in $\mathrm{SC} 1$.

[88] The results of SC6 are listed in Table 2 and 3. The total annual emission is close to that in $\mathrm{SC}$, although there are larger differences in the regional annual emissions. The largest difference is in South America, where a relative difference of $-18 \%$ is found. In most other regions, the difference between the annual emissions in SC6 and SC1 is around $10 \%$ or less. The a posteriori emissions in SC1 and SC6 are very close to each other. The annual regional emissions are within $15 \%$ of each other for most regions. However, the $\chi^{2}$ of both the a priori and a posteriori AI is rather different from that in SC1. There are two reasons. First, the off-diagonal covariance is included in SC6. Depending on the covariance matrix, the $\chi^{2}$ can either be larger or smaller than that in SC1. An increased $\chi^{2}$ can occur when the error of any two locations is more likely to be positively correlated. Therefore omitting the off-diagonal terms underestimates the total error. Second, the data points in SC6 are only a subset of those in SC1, which also causes a difference in $\chi^{2}$. Generally speaking, the uncertainty in SC6 is larger than that in SC1. Using fewer data points is 
one reason for this increase since fewer observational constraints are provided for the inverse model. Omitting the off-diagonal elements in the covariance matrix as is done in SC1 will tend to underestimate the observational uncertainties, resulting in a smaller a posteriori uncertainty.

\section{Summary}

[89] In this study, an inverse model is applied to improve current biomass burning emissions using the TOMS AI. The inverse model technique applied here optimizes the monthly biomass smoke emissions in the major biomass burning regions. The EP TOMS AI in 1997 is employed in the inverse model, while the DAO meteorology data in 1997 are employed in the transport model. While dust emissions are included in the transport model in order to obtain the correct modeled AI in the Sahel and in India they are not subject to optimization. Regions where absorbing aerosols are mainly dust aerosols are excluded from the inverse model in order to avoid adjusting biomass smoke emissions to optimize the discrepancy between the model and observations in these regions.

[90] The annual a posteriori biomass black carbon emissions in the base scenario are $6.31 \mathrm{Tg} / \mathrm{yr}$, only $13 \%$ higher than the a priori emissions. The increase of biomass emissions in the Southern Hemisphere is larger than that in the Northern Hemisphere. The a posteriori modeled AI generally shows better agreement with the observations in major biomass burning regions. The inverse model produces much larger emissions in Indonesia corresponding to the large fires in Indonesia in 1997. The difference between the a posteriori and a priori emissions is about a factor of 3 in Indonesia. A sensitivity test with increased a priori uncertainties resulted in higher emissions in Indonesia. Although the monthly a posteriori emissions are in the uncertainty range of the a priori emissions, the relative uncertainty in the monthly emissions is decreased. On the other hand, the absolute uncertainty in the monthly emissions is increased because of the larger Indonesian emissions from August through November.

[91] Better agreement between the model and observation in Indonesia suggests that the a priori uncertainty in Indonesia is underestimated in all scenarios except SC2. In other regions, the difference between $\mathrm{SC} 1$ and $\mathrm{SC} 2$ a posteriori emissions is relatively small. The uncertainty increases proportionally to the a priori uncertainty in SC2. The small decrease in the $\chi^{2}$ indicates that the ability of the inverse model to further minimize the difference between the observations and the model is limited because of the inability of the transport model to reproduce the spatial distribution of the observations on a small scale. The results of SC2 suggest that the a priori uncertainty is not the limiting factor in determining emissions except in Indonesia.

[92] Since the modeled AI is used in the optimization, the sensitivity of modeled AI due to different parameters is discussed. The modeled AI is more sensitive to the aerosol vertical distribution in the model and less sensitive to other parameters. Therefore the sensitivity of the a posteriori emissions to the aerosol height is examined in scenario SC3. SC3 has the smallest a posteriori emissions of all the scenarios, suggesting that the aerosol vertical distribution does indeed have a large impact on the inverse model results. On the other hand, comparison of the modeled aerosol vertical distribution and the observations only reveals a slight underestimation of the modeled aerosol height. The discrepancy between the modeled AOD and AI slope and the observation in SC3 suggests that the assumption that biomass burning aerosols due to large fires are lifted by $1 \mathrm{~km}$ causes an overestimation of aerosol height. The results of SC3 probably give a lower limit to the a posteriori emissions because of the model underestimation of aerosol height.

[93] A more restrictive cloud screening threshold also leads to smaller a posteriori emissions than those in the base scenario SC1, since the monthly mean TOMS AI is smaller. The effect of clouds depends on the vertical distribution of the aerosol and the clouds. Using a more restrictive cloud screening criteria reduces the contamination of the observed AI by clouds. However, it tends to remove strong aerosol events since both aerosols and clouds can increase the reflectivity. The cloud screening technique needs further study. For example, a weighting as a function of reflectivity could be added to the cost function to minimize the effect of cloud contamination instead of using the reflectivity to remove data with a cloudy scene.

[94] Allowing optimization of region 7 has almost no effect on the emissions in the first 6 regions, although the emissions in region 7 are decreased. Since the observational data points included in the inverse model are selected using the criteria that the AI value $\geq 0.4$, there are not enough observational points in the inverse model to constrain biomass burning emissions in region 7 . Relaxing this criterion is needed in order to produce more robust a posteriori emissions in region 7 .

[95] Compared to the base scenario where the offdiagonal elements describing the covariance between different locations is omitted, including off diagonal covariances in the inverse model results in almost identical annual emissions, while the monthly emissions are generally within $20 \%$ of the base scenario. When the offdiagonal covariance is neglected, the uncertainty of the observations is underestimated, causing an underestimation of the uncertainty of the a posteriori emissions. However, the sample size used for computing covariance is small in this study. The computed covariance may not represent an accurate value. Using the more recent TOMS data with larger total coverage can improve the estimation of covariance and the inverse model results.

[96] The total a posteriori $\mathrm{BC}$ emissions range from 5.68 to $6.87 \mathrm{Tg} / \mathrm{yr}$ in different scenarios for year 1997. The results of sensitivity scenarios suggest that a posteriori emissions are most sensitive to the assumed uncertainty of the a priori emissions, and the altitude of aerosol layer. The cloud screening criteria is also important. Since the TOMS $\mathrm{AI}$ is sensitive to the altitude of the aerosol layer, the inverse modeling result is subject to this uncertainty in modeling the aerosol vertical distribution. In addition, the TOMS AI is less sensitive to aerosols in the boundary layer. Smoke aerosols from peat burning and biofuel burning remaining in the boundary layer are probably not detected by TOMS. Therefore the inverse model results based on the TOMS AI probably only apply to open biomass emissions.

[97] Another limitation of this analysis is that biomass burning in temperate and boreal regions is not included in 
the a priori emissions. Optimizing boreal and temperate biomass burning using the TOMS AI is not exercised in this study because of the lack of information in the a priori emissions, and the limitation of the TOMS AI at higher latitudes. Duncan et al. [2003b] used the TOMS AI south of $60^{\circ} \mathrm{N}$ from late spring to early fall to study the interannual variabilities of global biomass emissions, including boreal and temperate fires. It is possible that the same approach can be applied to the inverse model to obtain boreal and temperate biomass burning emissions. This is especially interesting because the interannual variability of biomass burning in the temperate and boreal region is much more drastic than in the tropics. Area burned can vary by an order of magnitude in boreal regions alone. For example, 1998 was an extreme year for boreal fires, compared to the relatively calm 1997 [Amiro et al., 2001a, 2001b; Conard et al., 2002; Stocks et al., 2002; Kasischke and Bruhwiler, 2003; Soja et al., 2004]. At the same time, boreal regions are where the largest amount of terrestrial carbon resides [Apps et al., 1993; Zoltai and Martikainen, 1996; Alexeyev and Birdsey, 1998]. Fires in boreal and temperate regions play an important role in global carbon cycle, which warrants specific attention to these regions in a future investigation.

[98] Furthermore, the inverse model results are dependent on the a priori emissions and the forward model. The a posteriori emissions are subject to uncertainties in the model transport. However, this method provides an alternative way to assess the total biomass emission for a specific year and can avoid uncertainties present in bottom up techniques used to build emission inventories. Multiple years of biomass emissions can be generated using this approach in a future investigation to study the interannual variability of biomass burning.

\section{References}

Alexeyev, V. A., and R. A. Birdsey (1998), Carbon storage in forests and peatlands of Russia, Gen. Tech. Rep. NE 244, 137 pp., U.S. Dep. of Agric. For. Serv. Northeastern Res. Station, Radnor, Penn.

Amiro, B., J. Todd, B. Wotton, K. Logan, M. Flannigan, B. Stocks, J. Mason, D. Martell, and K. Hirsch (2001a), Direct carbon emissions from Canadian forest fires, 1959-1999, Can. J. For. Res., 31, 512-525.

Amiro, B. D., B. J. Stocks, M. E. Alexander, M. D. Flannigan, and B. M. Wotton (2001b), Fire, climate change, carbon and fuel management in the Canadian boreal forest, Int. J. Wildland Fire, 10(3-4), 405-413.

Anderson, B. E., W. B. Grant, G. L. Gregory, E. V. Browell, J. E. Collins Jr., G. W. Sachse, D. R. Bagwell, C. H. Hudgins, D. R. Blake, and N. J. Blake (1996), Aerosols from biomass burning over the tropical South Atlantic region: Distribution and impacts, J. Geophys. Res., 101, $24,117-24,138$.

Andreae, M. O. (1991), Biomass burning: Its history, use and distribution and its impact on environmental quality and global quality, in Global Biomass Burning, Atmospheric, Climatic, and Biospheric Implications, edited by J. S. Levine, pp. 3-21, MIT Press, Cambridge, Mass.

Andreae, M. O., and P. Merlet (2001), Emission of trace gases and aerosols from biomass burning, Global Biogeochem. Cycles, 15, 955-966.

Apps, M. J., W. A. Kurz, R. J. Luxmoore, L. O. Nilsson, R. A. Sedjo, R. Schmidt, L. G. Simpson, and T. S. Vinson (1993), Boreal forests and tundra, Water Air Soil Pollut., 70(1-4), 39-53.

Arellano, A. F., Jr., P. S. Kasibhatla, L. Giglio, G. R. van der Werf, and J. T. Randerson (2004), Top-down estimates of global CO sources using MOPITT measurements, Geophys. Res. Lett., 31, L01104, doi:10.1029/ 2003GL018609.

Balkanski, Y. J., D. J. Jacob, G. M. Gardner, W. C. Grausteinm, and K. K. Turekian (1993), Transport and residence times of tropospheric aerosols inferred from a global three-dimensional simulation of $210 \mathrm{~Pb}, J$. Geophys. Res., 98, 20,573-20,586.

Bergamaschi, P., R. Hein, M. Heimann, and P. J. Crutzen (2000a), Inverse modeling of the global $\mathrm{CO}$ cycle: 1 . Inversion of $\mathrm{CO}$ mixing ratios, J. Geophys. Res., 105, 1909-1927.
Bergamaschi, P., R. Hein, C. A. M. Brenninkmeijer, and P. J. Crutzen (2000b), Inverse modeling of the global CO cycle: 2 . Inversion of $13 \mathrm{C} / 12 \mathrm{C}$ and $18 \mathrm{O} / 16 \mathrm{O}$ isotope ratios, J. Geophys. Res., 105, 19291945.

Browell, E. V., et al. (1996), Ozone and aerosol distributions and air mass characteristics over the South Atlantic Basin during the burning season, J. Geophys. Res., 101, 24,043-24,068.

Colarco, P. R., O. B. Toon, O. Torres, and P. Rasch (2002), Determining the UV imaginary index of refraction of Saharan dust particles from Total Ozone Mapping Spectrometer data using a three-dimensional model of dust transport, J. Geophys. Res., 107(D16), 4289, doi:10.1029/ 2001JD000903.

Conard, S. G., A. I. Sukhinin, B. J. Stocks, D. R. Cahoon Jr., E. P. Davidenko, and G. A. Ivanova (2002), Determining effects of area burned and fire severity on carbon cycling and emissions in Siberia, Clim. Change, 55(1-2), 197-211.

Cooke, W. F., and J. J. N. Wilson (1996), A global black carbon aerosol model, J. Geophys. Res., 101, 19,395-19,409.

Crutzen, P. J., and M. O. Andreae (1990), Biomass burning in the tropics: Impact on atmospheric chemistry and biogeochemical cycles, Science, 250, 1669-1678.

Dana, M. T., and J. M. Hales (1976), Statistical aspects of the washout of polydisperse aerosols, Atmos. Environ., 10, 45-50.

Davison, P. S., D. L. Roberts, R. T. Arnold, and R. N. Colvile (2004), Estimating the direct radiative forcing due to haze from the 1997 forest fires in Indonesia, J. Geophys. Res., 109, D10207, doi:10.1029/ 2003JD004264.

Denning, A. S. (1994), Investigations of the transport, sources and sinks of atmospheric $\mathrm{CO}_{2}$ using a general circulation model, Ph.D thesis, Colo. State Univ., Fort Collins, Colo.

de Reus, M., F. Dentener, A. Thomas, S. Borrmann, J. Strom, and J. Lelieveld (2000), Airborne observations of dust aerosol over the North Atlantic Ocean during ACE-2: Indications for heterogeneous ozone destruction, J. Geophys. Res., 105, 15,263-15,275.

Dubovik, O., B. Holben, T. Eck, A. Smirnov, Y. Kaufman, M. King, D. Tanré, and I. Slutsker (2002), Variability of absorption and optical properties of key aerosol types observed in worldwide locations, J. Atmos. Sci., 59, 590-608.

Duncan, B. N., I. Bey, M. Chin, L. J. Mickley, T. D. Fairlie, R. V. Martin, and H. Matsueda (2003a), Indonesian wildfires of 1997: Impact on tropospheric chemistry, J. Geophys. Res., 108(D15), 4458, doi:10.1029/ 2002JD003195.

Duncan, B. N., R. V. Martin, A. C. Staudt, R. Yevich, and J. A. Logan (2003b), Interannual and seasonal variability of biomass burning emissions constrained by satellite observations, J. Geophys. Res., 108(D2), 4100, doi:10.1029/2002JD002378.

Enting, I. G. (1993), Inverse problems in atmospheric constituents studies: III. Estimating errors in surface sources, Inverse Probl., 9, $649-665$.

Enting, I. G., R. J. Francey, C. M. Trudinger, and H. Granek (1993), Synthesis inversion of atmospheric $\mathrm{CO}_{2}$ using the GISS Tracer Transport Model, Tech. Pap. 29, Commonw. Sci. and Ind. Res. Organ., Div. of Atmos. Res., Aspendale, Vic., Australia.

Fuelberg, H. E., J. D. VanAusdall, E. V. Browell, and S. P. Longmore (1996), Meteorological conditions associated with vertical distributions of aerosols off the west coast of Africa, J. Geophys. Res., 101, 24,105-24,015.

Galanter, M., H. Levy II, and G. R. Carmichael (2000), Impact of biomass burning on tropospheric $\mathrm{CO}, \mathrm{NO}_{\mathrm{x}}$ and $\mathrm{O}_{3}, J$. Geophys. Res., 105, 66336653.

Ginoux, P., M. Chin, I. Tegen, J. Prospero, B. Holben, O. Dubovik, and S. Lin (2001), Sources and distributions of dust aerosols simulated with the GOCART model, J. Geophys. Res., 106, 20,255-20,273.

Giorgi, F., and W. L. Chameides (1986), Rainout lifetime of highly soluble aerosols and gases as inferred from simulations with a general circulation model, J. Geophys. Res., 91, 14,367-14,376.

Grégoire, J.-M., K. Tansey, and J. M. N. Silva (2003), The GBA2000 initiative: Developing a global burned area database from SPOTVEGETATION imagery, Int., J. Remote Sens., 24, 1369-1376.

Hao, W. M., and M.-H. Liu (1994), Spatial and temporal distritution of tropical biomass burning, Global Biogeochem. Cycles, 8, 495-504.

Hao, W. M., M.-H. Liu, and P. J. Crutzen (1990), Estimates of annual and regional releases of $\mathrm{CO}_{2}$ and other race gases to the atmosphere from fires in the tropics, based on the FAO statistics for the period 1975-1980, in Fire in the Tropical Biota, edited by J. C. Goldammer, pp. 440-462, Springer, New York.

Haywood, J. M., S. R. Osborne, P. N. Francis, A. Keil, P. Formenti, M. O. Andreae, and P. H. Kaye (2003), The mean physical and optical properties of regional haze dominated by biomass burning aerosol measured from the C-130 aircraft during SAFARI 2000, J. Geophys. Res., 108(D13), 8473, doi:10.1029/2002JD002226. 
Hein, R., P. J. Crutzen, and M. Heimann (1997), An inverse modeling approach to investigate the global methane cycle, Global Biogeochem. Cycles, 11, 43-76.

Hély, C., P. R. Dowty, S. Alleaume, K. K. Caylor, S. Korontzi, R. J. Swap, H. H. Shugart, and C. O. Justice (2003), Regional fuel load for two climatically contrasting years in southern Africa, J. Geophys. Res., 108(D13), 8475, doi:10.1029/2002JD002341.

Herman, B. M., and S. R. Browning (1965), A numerical solution to the equation of radiative rranfer, J. Atmos. Sci., 22, 559-566.

Herman, J. R., and E. Celarier (1997), Earth's surface reflectivity climatology at 340-380 nm from TOMS data, J. Geophys. Res., 102, 28,00328,012 .

Herman, J. R., P. K. Bhartia, O. Torres, C. Hsu, C. Seftor, and E. CElarier (1997), Global distribution of UV-absorbing aerosols from Nimbus 7/ TOMS data, J. Geophys. Res., 102(D14), 16,911-16,922.

Hobbs, P. V., J. S. Reid, R. A. Kotchenruther, R. J. Ferek, and R. Weiss (1997), Direct radiative forcing by smoke from biomass burning, Science, $275,1776-1778$.

Hsu, N. C., J. R. Herman, O. Torres, B. N. Holben, D. Tanre, T. F. Eck, A. Smirnov, B. Chatenet, and F. Lavenu (1999), Comparisons of the TOMS aerosol index with Sun-photometer aerosol optical thickness: Results and applications, J. Geophys. Res., 104, 6269-6279.

Ito, A., and J. E. Penner (2004), Global estimates of biomass burning emissions based on satellite imagery for the year 2000, J. Geophys. Res., 109, D14S05, doi:10.1029/2003JD004423.

Justice, C. O., L. Giglio, S. Korontzi, J. Owens, J. T. Morisette, D. Roy, J. Descloitres, S. Alleaume, F. Petitcolin, and Y. Kaufman (2002), The MODIS fire products, Remote Sens. Environ., 83(1-2), 244-262.

Kasischke, E. S., and L. P. Bruhwiler (2003), Emissions of carbon dioxide, carbon monoxide, and methane from boreal forest fires in 1998, J. Geophys. Res., 108(D1), 8146, doi:10.1029/2001JD000461.

Kaufman, Y. J., C. J. Tucker, and I. Fung (1990), Remote sensing of biomass burning in the tropics, J. Geophys. Res., 95, 9927-9939.

Koepke, P., M. Hess, I. Schult, and E. P. Shettle (1997), Global aerosol data set, Tech. Rep. 243, Max-Planck Inst. for Meteorol., Hamburg, Germany.

Lacaux, J. P., J. M. Brustet, R. Delmas, J. C. Menaut, L. Abbadie, B. Bonsang, H. Cahier, J. G. R. Baudet, M. O. Andreae, and G. Helas (1995), Biomass burning in the tropical savannas of Ivory Coast: An overview of the field experiment Fire of Savannas (FOS/DECAFE'91), J. Atmos. Chem., 22, 195-216.

Levine, J. S. (1999), 1997 fires in Kalimantan and Sumatra, Indonesia: Gaseous and particulate emissions, Geophys. Res. Lett., 26, 815-818.

Lin, S. J., and R. B. Rood (1996), Multidimensional flux-form semiLagrangian transport schemes, Mon. Weather Rev., 124, 2046-2070.

Liousse, C., J. E. Penner, C. Chuang, J. J. Walton, and H. Eddleman (1996), A global three-dimensional model study of carbonaceous aerosols, J. Geophys. Res., 101, 19,411-19,432.

Liu, H., D. J. Jacob, I. Bey, and R. M. Yantosca (2001), Constraints from ${ }^{210} \mathrm{~Pb}$ and ${ }^{7} \mathrm{Be}$ on wet deposition and transport in a global threedimensional chemical tracer model driven by assimilated meteorological fields, J. Geophys. Res., 106, 12,109-12,128.

Malinggreau, J.-P., C. J. Tucker, and N. Laporte (1989), AVHRR for monitoring global tropical deforestation, Int. J. Remote Sens., 10, 855857

McPeters, R. D., et al. (1998), Earth probe Total Ozone Mapping Spectrometer (TOMS) data products user's guide, NASA Ref. Publ. 1998 206895.

Page, S. E., F. Siegert, J. O. Rieley, H.-D. V. Boehm, A. Jaya, and S. Limin (2002), The amount of carbon released from peat and forest fires in Indonesia during 1997, Nature, 420, 61-65

Patterson, E. M., D. A. Gillete, and B. H. Stockton (1977), Complex index of refraction between 300 and $700 \mathrm{~nm}$ for Saharan aerosols, J. Geophys. Res., 82, 3153-3160

Penner, J. E., C. C. Chuang, and K. E. Grant (1998), Climate forcing by carbonaceous and sulfate aerosols, Clim. Dyn., 14, 839-851.

Penner, J. E., et al. (2001), Aerosols and radiative forcing, in Intergovernmental Panel on Climate Change, Report to IPCC from the Scientific Assessment Working Group (WGI), pp. 289-349, Cambridge Univ. Press, New York.

Penner, J. E., et al. (2002), A comparison of model- and satellite-derived optical depth and reflectivity, J. Atmos. Sci., 59, 441-460.

Podgorny, I. A., F. Li, and V. Ramanathan (2003), Large aerosol radiative forcing due to the 1997 Indonesian forest fire, Geophys. Res. Lett., 30(1), 1028, doi:10.1029/2002GL015979.

Radke, L. F., D. A. Hegg, J. H. Lyon, C. A. Brock, P. V. Hobbs, R. Weiss, and R. Rasmussen (1988), Airborne measurements on smoke from biomass burning, in Aerosols and Climate, edited by P. V. Hobbs and M. P. McCormick, pp. 411-422, A. Deepak, Hampton, Va.
Remer, L. A., Y. J. Kaufman, B. N. Holben, A. M. Thompson, and D. McNamara (1998), Biomass burning aerosol size distribution and modeled optical properties, J. Geophys. Res., 103, 31,879-31,891.

Richardson, J. L. (1994), An investigation of large-scale tropical biomass burning and the impact of its emissions on atmosperic chemistry, Ph.D. thesis, Georgia Inst. of Technol., Atlanta.

Ross, J. L., P. V. Hobbs, and B. Holben (1998), Radiative characteristics of regional hazes dominated by smoke from biomass burning in Brazil: Closure tests and direct radiative forcing, J. Geophys. Res., 103, 31,925-31,941.

Roy, D. P., P. E. Lewis, and C. O. Justice (2002), Burned area mapping usig multi-temporal moderate spatial resolution data-A bi-direction reflectance model-based expecation approach, Remote Sens. Environ., 83, $263-286$

Scholes, M., and M. O. Andreae (2000), Biogenic and pyrogenic emissions from Africa and their impact on the global atmosphere, Ambio, 29, 23-29.

Seiler, W., and P. J. Crutzen (1980), Estimates of gross and net fluxes of carbon between the biosphere and the atmosphere from biomass burning, Clim. Change, 2, 207-247.

Setzer, A. W., and M. C. Pereira (1991), Amazon biomass burnings in 1987 and their tropospheric emissions, Ambio, 20, 19-22.

Simon, M., S. Plummer, F. Fierli, J. Hoelzemann, and O. Arino (2004), Burnt area detection at global scale using ATSR-2: The GLOBSCAR products and their qualification, J. Geophys. Res., 109, D14S02, doi:10.1029/2003JD003622.

Sinyuk, A., O. Torres, and O. Dubovik (2003), Combined use of satellite and surface observations to infer the imaginary part of refractive index of Saharan dust, Geophys. Res. Lett., 30(2), 1081, doi:10.1029/ 2002GL016189.

Slinn, W. G. N. (1982), Predictions from particle deposition to vegetative surfaces, Atmos. Environ., 16, 1785-1794.

Soja, A. J., W. R. Cofer III, H. H. Shugart, A. I. Sukhinin, P. W. Stackhouse Jr., D. J. McRae, and S. G. Conard (2004), Estimating fire emissions and disparities in boreal Siberia (1998 through 2002), J. Geophys. Res., 109, D14S06, doi:10.1029/2004JD004570.

Stocks, B. J., et al. (2002), Large forest fires in Canada, 1959-1997, J. Geophys. Res., 108(D1), 8149, doi:10.1029/2001JD000484.

Tarantola, A., and B. Valette (1982a), Generalized nonlinear inverse problems solved using the least square criterion, Rev. Geophys., 20, $219-232$

Tarantola, A., and B. Valette (1982b), Inverse problems-Quest of information, J. Geophys., 50, 159-170.

Torres, O., P. K. Bharita, J. R. Herman, Z. Ahmad, and J. Gleason (1998), Derivation of aerosol properties from satellite measurements of backscattered ultraviolet radiation: Theoretical basis, J. Geophys. Res., 103, 17,099-17,110.

Torres, O., P. K. Bhartia, J. R. Herman, A. Sinyuk, and B. Holben (2002), A long term record of aerosol optical thickness from TOMS observations and comparison to AERONET measurements, J. Atmos. Sci., 59, 398413 .

van der Werf, G. R., J. T. Randerson, G. J. Collatz, and L. Giglio (2003), Carbon emissions from fires in tropical and subtropical ecosystems, Global Change Biol., 9, 547-562.

van der Werf, G. R., J. T. Randerson, G. J. Collatz, L. Giglio, P. S. Kasibhatla, A. F. Arellano Jr., S. C. Olsen, and E. S. Kasischke (2004), Continental-scale partitioning of fire emissions during the 1997 to 2001 El Niño/La Niña period, Science, 303, 73-76.

Ward, D. E., A. W. Setzer, Y. J. Kaufman, and R. A. Rasmussen (1991), Characteristics of smoke emissions from biomass fires of the Amazon region-base-A experiment, in Global Biomass Burning: Atmospheric, Climatic, and Biospheric Implications, edited by J. S. Levine, pp. 394-402, MIT Press, Cambridge, Mass.

Zhang, L., S. Gong, J. Padro, and L. Barrie (2001), A size-segregated particle dry deposition scheme for an atmospheric aerosol module, Atmos. Environ., 35, 549-560.

Zoltai, S. C., and P. J. Martikainen (1996), The role of forested peatlands in the global carbon cycle, in Forest Ecosystems, Forest Management and the Global Carbon Cycle, vol. 140, edited by M. J. Apps and D. T. Price, pp. 47-58, Springer, New York.

J. E. Penner, Department of Atmospheric, Oceanic and Space Sciences, University of Michigan, Ann Arbor, MI 48109, USA. (penner@mail. umich.edu)

O. Torres, Joint Center for Earth Systems Technology, University of Maryland, Baltimore County, Baltimore, MD 21250, USA.

S. Zhang, NASA Goddard Institute for Space Studies, New York, NY 10025, USA. (szhang@giss.nasa.gov) 